\title{
Self-Efficacy, Trait Mindfulness, and Self-Compassion as Predictors of Risk of Substance Use Relapse
}

Jonathan Nauser

West Virginia University, jwn0003@mix.wvu.edu

Follow this and additional works at: https://researchrepository.wvu.edu/etd

Part of the Counseling Psychology Commons

\section{Recommended Citation}

Nauser, Jonathan, "Self-Efficacy, Trait Mindfulness, and Self-Compassion as Predictors of Risk of Substance Use Relapse" (2021). Graduate Theses, Dissertations, and Problem Reports. 8148.

https://researchrepository.wvu.edu/etd/8148

This Dissertation is protected by copyright and/or related rights. It has been brought to you by the The Research Repository @ WVU with permission from the rights-holder(s). You are free to use this Dissertation in any way that is permitted by the copyright and related rights legislation that applies to your use. For other uses you must obtain permission from the rights-holder(s) directly, unless additional rights are indicated by a Creative Commons license in the record and/ or on the work itself. This Dissertation has been accepted for inclusion in WVU Graduate Theses, Dissertations, and Problem Reports collection by an authorized administrator of The Research Repository @ WVU.

For more information, please contact researchrepository@mail.wvu.edu. 
Self-Efficacy, Trait Mindfulness, and Self-Compassion as Predictors of Risk of Substance Use Relapse

Jonathan Nauser, M.S.

Dissertation submitted to the College of Education and Human Services at West Virginia University in partial fulfillment of the requirements for the degree of Doctor of Philosophy in Counseling Psychology

\author{
Monica Leppma, Ph.D., Chair \\ Jeff Daniels, Ph.D. \\ Laura Lander, MSW, LICSW \\ Lisa Platt, Ph.D. \\ Christine Schimmel, Ed.D.
}

Department of Counseling and Learning Sciences

\author{
Morgantown, West Virginia
}

2020

Keywords: mindfulness; self-compassion; substance abuse; relapse; self-efficacy

Copyright 2020 Jonathan W. Nauser 


\begin{abstract}
Self-Efficacy, Trait Mindfulness, and Self-Compassion as Predictors of Risk of Substance Use Relapse

Jonathan Nauser, M.S.

Previous research has demonstrated relationships among mindfulness, self-efficacy, and substance use relapse. Contrasting research has found mindfulness and self-efficacy are not consistently negatively associated with substance use relapse demonstrating a need for further research. An additional factor that has been found to associated with substance use is selfcompassion; however, it has yet to be examined in relation to the process of relapse. The current study assessed self-efficacy, self-compassion, and mindfulness and their associations with substance use relapse, with the aim of predicting relapse risk. Higher levels of relapse risk were found to be negatively associated with self-efficacy, trait mindfulness, and self-compassion. Additionally, through a hierarchical regression, self-efficacy was found to significantly predict relapse risk. After adding trait mindfulness into the regression model, significantly more variance was explained for relapse risk. However, when self-compassion was added into the model, it was found to be still predictive of relapse risk but did not add a significant amount of variance to the model. Findings suggest that individuals with higher levels of self-compassion, self-efficacy and trait mindfulness are less likely to relapse while in recovery from substance use. The current study's findings indicate these three variables play a role in substance use relapse and have potential to be utilized in integrated relapse prevention treatments. Implications for substance use programs and integrated treatments are discussed, as well as strengths and limitations of the study and suggestions for future research.
\end{abstract}




\section{DEDICATION}

This dissertation is dedicated to all of those who take part in the support and treatment of individuals suffering from substance use, the instrumental and fortuitous substance use clinics, and to those who continue to have difficulties in their road to recovery. 


\section{ACKNOWLEDGEMENTS}

First, it goes without saying, gratitude is owed to my support system and loved ones that have and continue to believe in me, motivate me, and push me through all of my years in academics. I cannot thank my family enough for their continued love and support they have continually expressed throughout this long journey. I am thankful for my friends within the program and cohort that have taken part in my academic development and for becoming "aunts and uncles" in my family. Your support and love are unparalleled and will always be remembered. Thanks to their motivation and encouragement, I have made several academic milestones that I would have never have dreamt possible. Having all of you as companions has been the greatest gift of my academic career.

My journey within academics began in 2009 and has had an unshaking foundation from its beginning. This foundation is comprised of friends from the state of Missouri that have continued bonds across hundreds of miles and who have never failed to communicate their love and support. All of you are family to me and your unwavering love remains something indescribable and unable to be reciprocated in full. A special recognition to my wife, Samantha, and my daughter, Felicity. My small family has been through wonderful and difficult times throughout my years at WVU. Through it all, my wife and my daughter continue to be my largest supporters and my greatest loves in this world. They are my inspiration to wake up every

morning and see the world for what they make it. To be present for this is the greatest gift. Their love, patience, and tolerance have largely contributed to my achievements and continue to be appreciated.

I would also like to acknowledge and thank the members of my committee, Dr. Monica Leppma, Dr. Jeff Daniels, Laura Lander, Dr. Christine Schimmel, and Dr. Lisa Platt. Without 
your patience and guidance, I would not be the researcher and clinician that I have become. In addition, I am grateful for the incredible supervision I have received from each of my supervisors at WVU Hospital Systems. They have all taken part in the development of my career path as a health service psychologist. With the guidance of faculty and supervisors, I have personally been able to make large strides in conquering anxieties and combining my passions with my career aspirations. 


\section{TABLE OF CONTENTS}

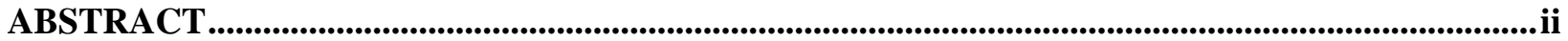

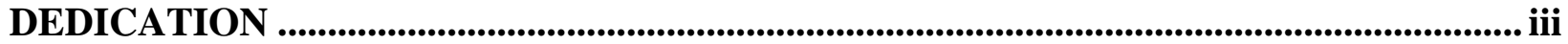

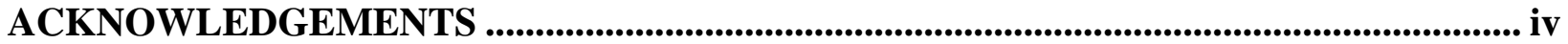

LIST OF TABLES AND FIGURES........................................................................................ viii

CHAPTER 1: INTRODUCTION AND LITERATURE REVIEW ......................................... 1

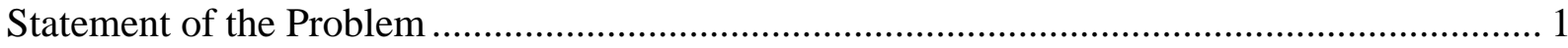

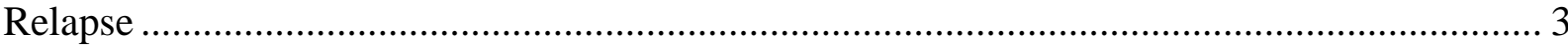

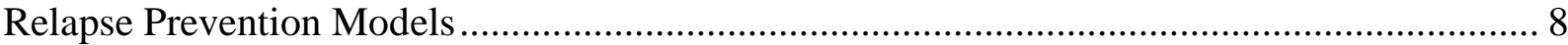

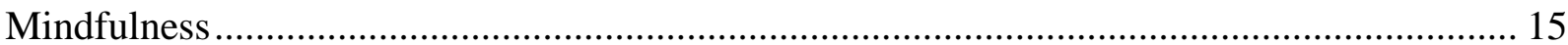

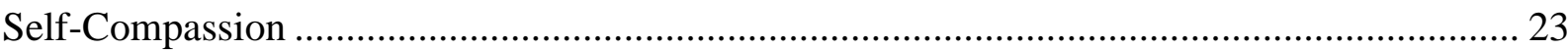

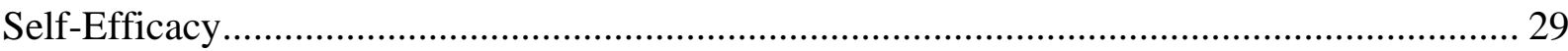

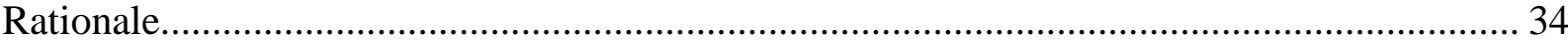

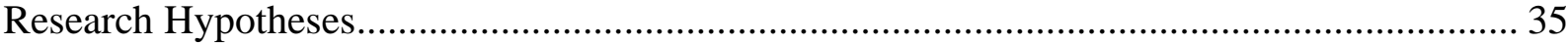

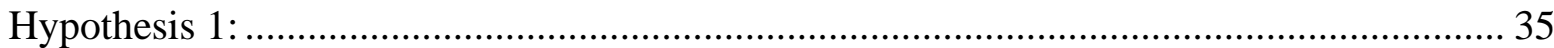

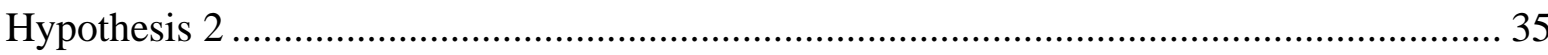

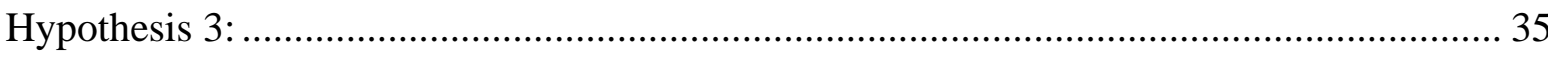

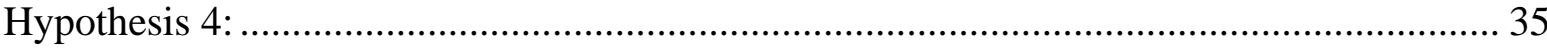

CHAPTER 2: METHODS .................................................................................................................. 37

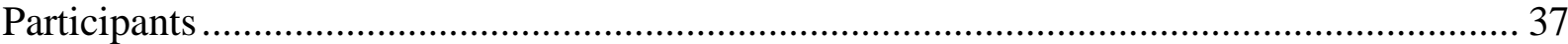

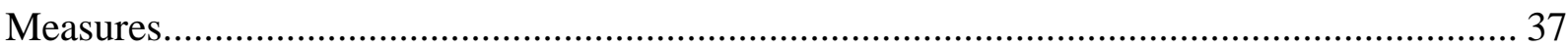

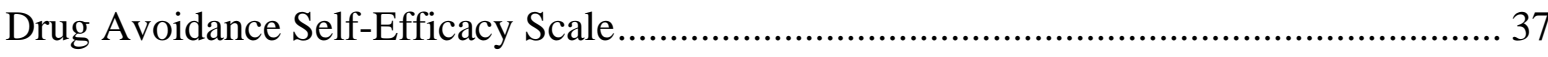

Five Facet Mindfulness Questionnaire-Short Form .................................................... 39

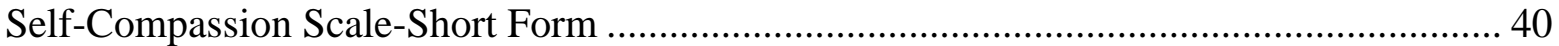

Advanced Warning of Relapse Scale ......................................................................... 41

Substance Use Relapse and Demographics .............................................................. 43

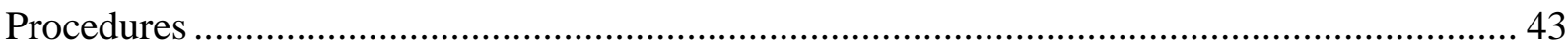

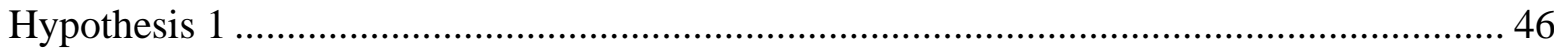

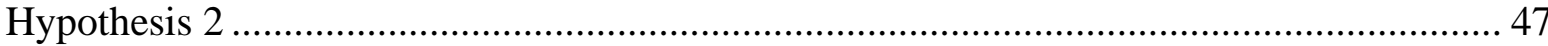

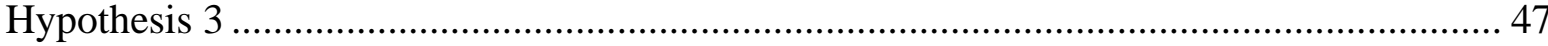

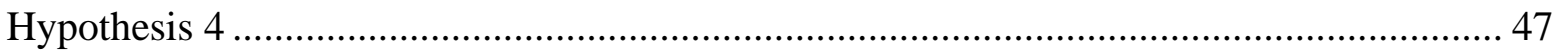

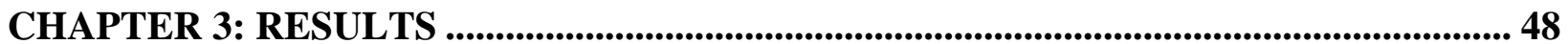




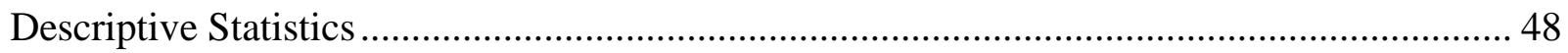

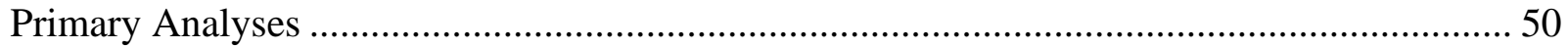

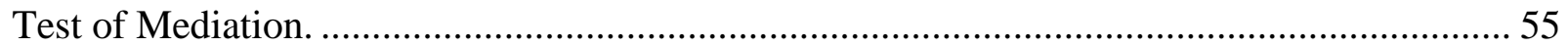

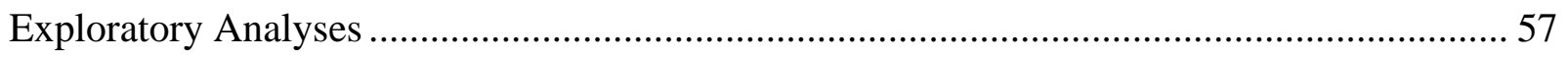

CHAPTER 4: DISCUSSION ................................................................................................ 57

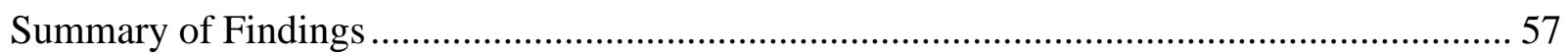

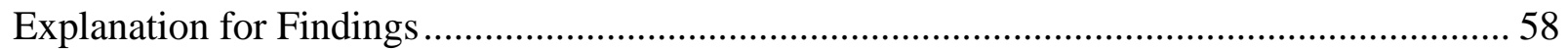

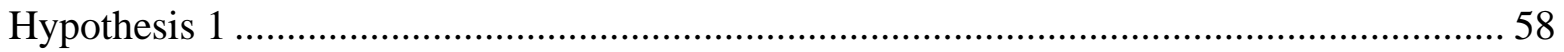

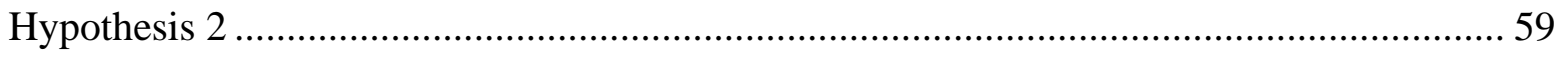

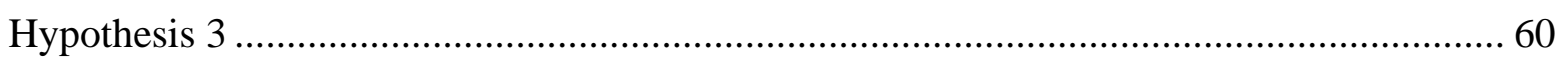

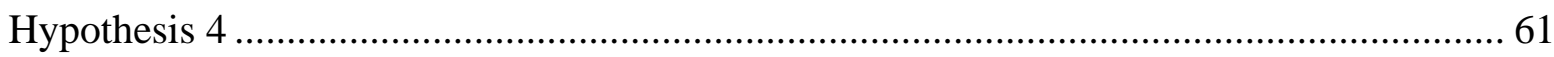

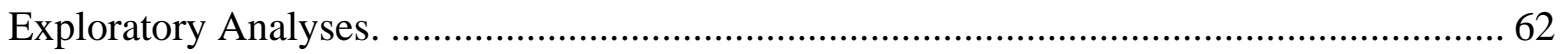

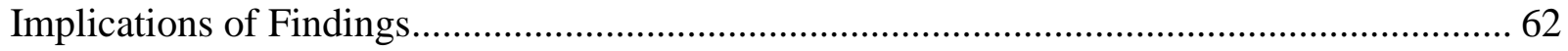

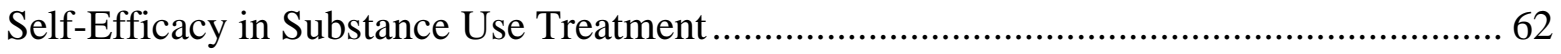

Mindfulness in Substance Use Treatment ..................................................................... 64

Self-Compassion in Substance Use Treatment............................................................... 66

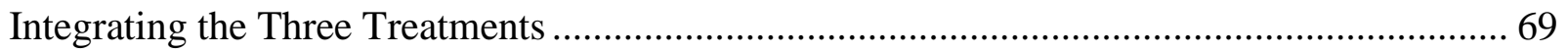

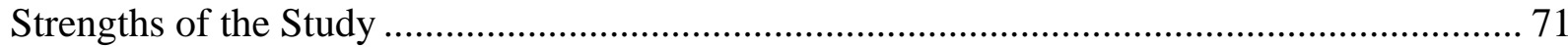

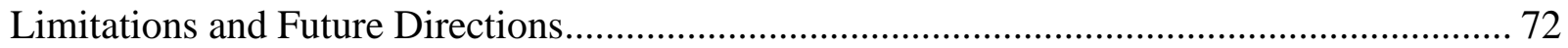

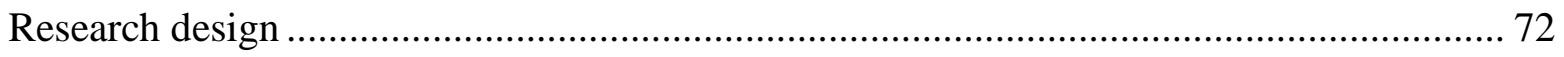

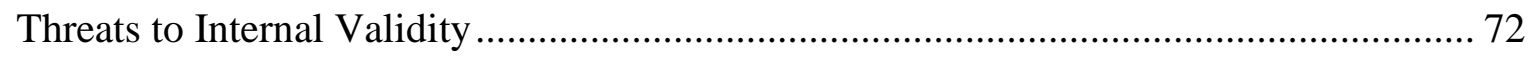

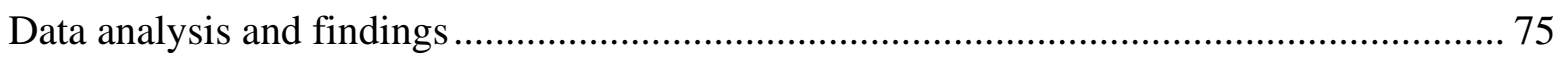

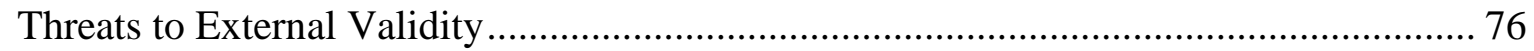

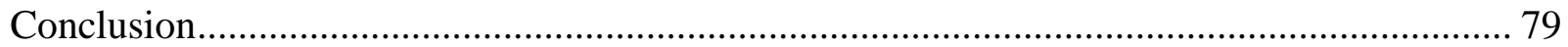

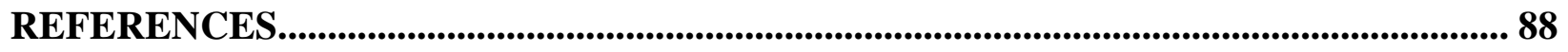

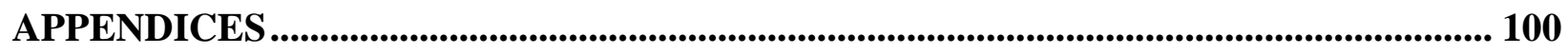

Appendix A: Drug Avoidance Self-Efficacy Scale......................................................... 100

Appendix B: Five Facet Mindfulness Questionnaire-Short Form .................................... 103

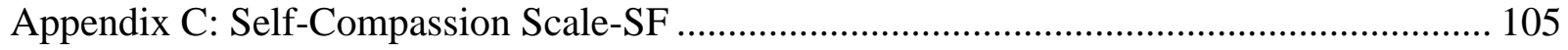

Appendix D: Advanced Warning of Relapse Scale .................................................... 106

Appendix E: Substance Abuse Relapse and Demographics ............................................ 109

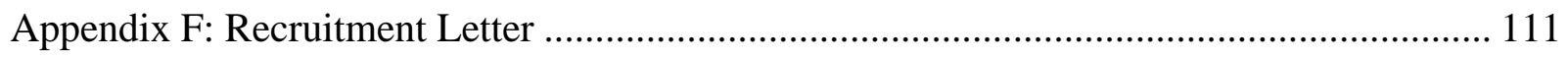


Appendix E: Informed Consent Form ....................................................................... 112

Human Research Protocol Only Minimal Risk Consent Form (With HIPAA) ................. 112

\section{LIST OF TABLES AND FIGURES}




\section{CHAPTER 1: INTRODUCTION AND LITERATURE REVIEW}

Substance use has and continues to be a pervasive problem within society. The number of individuals with substance use disorders that return to using their substance of choice ranges from 70 to $80 \%$ (Brandon, Vidrine, \& Litvin, 2007; Miller, Westerberg, Harris, \& Tonigan, 1996; Walton, Blow, Bingham, \& Chermack, 2003). Although substance use relapse is still considered to be common in the process of recovery, extant research is still not able to fully explain the contributing factors in a relapse. Moreover, the definitions of relapse vary in complexity and detail. For example, Hunt, Barnett, and Branch (1971) defined relapse as a return of the problem behavior, whereas other researchers defined relapse as a static, discrete, or end state (Donovan, 1996; Marlatt, 1985; Miller, 1996). Regardless of how relapse is defined, Polivy and Herman (2002) stated that for individuals who attempt to change their behavior in a certain direction, lapses will occur that often lead to relapse. Given the large frequency of relapse for individuals recovering from substance use disorders, it is evident that the issue has persisted across decades and research is needed to understand this complex process. The occurrence of relapse has costly effects for those trying to recover from a substance use disorder (SUD) their families and society.

\section{Statement of the Problem}

The problem of substance use affects multiple different areas of our society, such as the prison system, the workforce, and healthcare. Regarding the economic cost of caring for those with a substance use disorder, the National Institute on Drug Abuse (NIDA, 2017) reported more than $\$ 740$ billion was spent on substance use-related concerns related to crime, lost work productivity, and health care as of 2017. Substance use has not only had a dramatic economic effect, but it also has cost the lives of thousands within the United States. In 2010, there were an 
estimated 40,000 drug overdose deaths involving cocaine or opioids and, most recently, the number of drug overdose deaths involving those specific substances has more than doubled (NIDA, 2017). In 2016, there were some estimated 64,000 drug overdose deaths with just over 20,000 of those attributed to the sharp increase in deaths related to fentanyl and fentanyl analogs (NIDA, 2017). The prevalence of using an illicit substance has also increased over time. As of 2013, an estimated 24.6 million Americans 12 years of age or older (9.4\% of population) have used an illicit drug in the past month (NIDA, 2015). This prevalence statistic has increased by a full percent of the population since 2002 (NIDA, 2015). The Center for Disease Control (CDC) estimated that 114 people die per day of drug overdoses and an estimated 6,748 people will be sent to hospital emergency rooms for treatment per day as well (Rudd, Seth, David, \& Scholl, 2016). A separate statistic from the Substance Abuse and Mental Health Services Administration (SAMHSA) found that $90 \%$ of people who needed substance use treatment did not receive it. Given these recent statistics, it is evident substance use has been and continues to be an ongoing issue in society which demands numerous resources and continued effort to sustain recovery. One method to combat addiction is by understanding what propels the addictive process as well as what factors interrupt recovery and lead into relapse. The current research identifies variables that have been associated with substance use relapse in previous literature and explores another variable that possibly plays a role in this process.

Current literature identifies mindfulness (Appel \& Kim-Appel, 2009; Bowen \& Enkema, 2014; Fernandez, Wood, Stein, \& Rossi, 2010; Karyadi, VanderVeen, \& Cyders, 2014; Leigh, Bowen, \& Marlatt, 2005; Leigh \& Neighbors, 2009; Robinson, Ladd, \& Anderson, 2014) and self-efficacy (Ilgen, McKellar, \& Moos, 2007; Ilgen, McKellar, \& Tiet, 2005; Ilgen, Tiet, Finney, \& Moos, 2006; Moos \& Moos, 2006; Trucco, Connery, Griffen, \& Greenfield, 2007) as 
contributing factors in relapse, but with mixed results. Research has indicated that mindfulness is negatively related to alcohol use (Fernandez et al., 2010), severity of dependence (Bowen \& Enkema, 2014), and lifetime alcohol and marijuana use in clinical samples (Robinson et al., 2014); however, other studies have found that mindfulness has been positively correlated with heavy substance use (Leigh et al., 2005; Leigh \& Neighbors, 2009). Other researchers, such as Burling, Reilly, Moltzen, and Ziff (1989) found self-efficacy levels to be higher in abstainers than those who relapse in their substance use, but self-efficacy was not predictive of positive treatment outcome in a follow-up interview. Other self-efficacy research has found self-efficacy evaluations to be predictive of successful abstinence (DiClemente, 1986). Ilgen et al. (2005) and Ilgen et al. (2006) also added significant mixed findings in the relationship between self-efficacy and relapse. Ilgen et al. (2005) found that self-efficacy was not always predictive of abstinence after a year follow-up, while Ilgen et al. (2006) found that self-efficacy was a strong predictor of a larger percent of abstinent days in one year when combined with a strong therapeutic alliance. Researchers have just begun to examine the related construct of self-compassion in relation to substance use (Brooks, Kay-Lambkin, Bowman, \& Childs, 2012; Miron et al., 2014; Rendon, 2007; Tanaka et al., 2011; Vettese et al., 2011), but have not explored self-compassion as a predictor of relapse risk. The proposed study will assess self-efficacy, self-compassion, and mindfulness and their associations with substance use relapse, with the aim of predicting relapse risk.

\section{Relapse}

Since the 1970s, research has been conducted in efforts to operationalize and define what constitutes a substance use relapse (Hunt, Barnett, \& Branch, 1971; Marlatt \& George, 1984; 
Miller, 1996). Behavioral research has defined relapse as any return to the problem behavior (Hunt et al., 1971), whereas those who practice within the medical model have defined relapse as a discrete or single event (Marlatt \& George, 1984; Miller, 1996). Marlatt and George (1984) broadened the terminology and defined relapse as a dynamic process that ultimately results in a return to previous behavior patterns. For the purposes of this investigation, relapse will be examined as more of a dynamic process that involves many internal and external issues (Brown, Vik, \& Creamer, 1989; El, Gaily, El, \& Bashir, 2004; Ramo, Anderson, Tate, \& Brown, 2005; Uslaner, Kalechstein, Richter, Ling, \& Newton, 1999). This definition was chosen for this investigation due to the purposeful examination of internal factors.

Previous investigators have tried to answer the question as to why those recovering from addiction relapse back into substance use and continue this pattern of behavior. Scholars in this field have often attributed the event to internal triggers, such as depressive symptoms (Uslaner et al., 1999), conflict/life stress, negative emotional states, and active emotional states (Caselli, Ferretti, Leoni, Rebecchi, Rovetto, \& Spada, 2010; Ramo et al., 2005). The internal triggers that contribute to substance use relapse were explored by Uslaner et al. (1999). The researchers recruited 17 cocaine-dependent men to be assessed for psychiatric symptoms on an addiction severity index via a brief symptom inventory during a 14-day inpatient substance use recovery program. Participants with higher depression scores were more likely to report feelings of failure, anhedonia, guilt, self-hatred, self-blame, indecisiveness, low motivation, and fatigue. In this study, these symptoms appeared to be associated with the high induced by cocaine and subsequent discontinuation of the drug, and supported to be possible indicators for a relapse. Uslaner et al. (1999) specifically focused on cocaine dependent men, limiting the application of their findings to broader populations with various addictions other than cocaine dependence. 
External triggers linking to substance use relapse include situational factors (e.g., socializing with others abusing substances, individuals' reported most important person abstaining from drugs and alcohol, social environment) (Brown, Vik, \& Creamer, 1989), testing personal control, social pressure, urge and temptations (El, Gaily, El, \& Bashir, 2004).

Another population that was examined for contributors of relapse included adolescents diagnosed with alcohol and other drug dependencies (Brown et al., 1989). In this qualitative study, the researchers identified the circumstances of adolescent relapse to clarify any differences between adult and adolescent relapse to develop treatment programs for teens. Researchers obtained consent from 75 adolescents and their parents to participate in a structured interview regarding sociodemographic, medical, psychiatric, and drinking and drug use information for the adolescent and his or her family. These same adolescent participants were assessed three months and six months posttreatment. Areas that were assessed included alcohol and drug use during the follow-up period, physical, social, and interpersonal characteristics of initial relapse experiences, and functioning in major life areas. One third of relapsed adolescents in this study reported that they were attempting to cope with a negative affective state $(16.7 \%$ depression, $13.3 \%$ anger/frustration, and $3.3 \%$ other) at the time of the relapse (Brown et al., 1989). Negative affective states have been found to be significant pre-cursors to relapse in adults and adolescents; however, depression is a complicated emotional state that warrants further analysis of what specific symptoms of depression are related to relapse. The previously mentioned research highlights not only the importance of situational factors in the contribution of relapse, but also highlights the importance of other contributing factors being currently researched, such as internal issues and active emotional states at the time of relapse. 
Previous studies have shown that there are differences and similarities between populations in terms of pre-cursors to relapse, both internally and externally. Ramo et al. (2005) examined a different population of adolescents with comorbid psychiatric disorders and factors associated with the relapse process for substance use. They aimed to clarify the role of psychiatric symptom severity and situational self-efficacy in a population of youth in a substance use treatment program. Adolescents receiving inpatient treatment for alcohol and other SUDs along with a co-occurring diagnosed disorder were selected to participate in a Contextual Cue Assessment for Relapse interview within the first six months following treatment. This interview assessed interpersonal, intrapersonal, and other contextual information related to the relapse episode. Self-efficacy was also measured using a questionnaire that assessed coping self-efficacy in relation to adolescent risk for relapse situations. In their findings, self-efficacy and psychiatric symptoms both significantly predicted relapse following a conflict/life stress experience and negative emotional states (Ramo et al., 2005). Taken together, these results suggest that adolescents with limited self-efficacy and present comorbid psychiatric symptoms appeared most vulnerable to relapse in circumstances characterized by conflict/life stress and negative emotional states. From Ramo et al. (2005), not only are situational factors strong precursors for relapse in adolescents, but characteristics, such as self-efficacy, appear to be also.

El et al. (2004) found congruent findings with Ramo et al.’s (2005) study in their examination of the role of self-efficacy in relapse, specifically measuring differences between participants addicted to alcohol and heroin across relapse dimensions. A sample of 105 individuals with substance use disorders within Al-Amal hospital in Jeddah, Saudi Arabia were given two self-report questionnaires that assessed for the clients' high-risk situations for alcohol and other drug relapse and their ability to cope with these high-risk situations in everyday life. 
For participants that identified as having an alcohol use disorder, results were found to be nonsignificant in terms of differences in their self-efficacy in high-risk situations for relapse, whereas participants who identified as heroin addicts were found to have poorer self-efficacy levels to resist urge in social and peer interactions (El et al., 2004). These mixed results suggest further research is needed into how self-efficacy contributes to relapse, and what other factors might play a role in relapse as well. From the previous findings, it is a fair assumption to state that believing in one's self and one's performance can serve to protect someone from relapse.

A separate examination sought to determine the predictive value of rumination in predicting the absence or presence of alcohol use (Caselli et al., 2010). A sample of 80 outpatient participants were administered a battery of questionnaires including the Ruminative Responses Scale of the Responses Styles Questionnaire, which measured the tendency to ruminate in response to depression. Depression, rumination, and alcohol consumption level were measured before the first treatment session, and drinking status and level of alcohol use were assessed at three, six, and 12-month follow ups. It was found that rumination had higher predictive power for drinking status compared to baseline alcohol use and baseline depression in the three, six, and 12-month follow ups (Caselli et al., 2010). Further correlational analyses found that higher levels of rumination were found to be positively correlated with level of alcohol use following treatment (Caselli et al, 2010).

The previously reviewed research regarding relapse illustrates that there are multiple contributing factors to this complex process. Situational factors such as socializing with others abusing substances (Brown et al., 1989) play a significant role as well as internal factors (Uslaner et al., 1999). Negative affective states (Brown et al., 1989), rumination (Caselli et al., 2010), and self-efficacy (El et al., 2004; Ramo et al, 2005) have also been found to key 
motivators to relapse. However, the current research intends to clarify the predictive role of selfefficacy in relapse risk. Prior to demonstrating other internal factors' roles in relapse, significant factors must be discussed in their utility of relapse prevention.

\section{Relapse Prevention Models}

Cognitive-behavioral treatment interventions are commonly used within relapse prevention models. Marlatt and Gordon (1985) conceptualized relapse to include cognitive, behavioral, and affective mechanisms underlying the process. The authors also conceptualized addiction as stemming from maladaptive habit patterns rather than solely physiological responses to the addictive substance (Marlatt \& Gordon, 1985). From this conceptualization of addiction and relapse, Marlatt and Gordon (1985) suggested that relapse prevention occurs at a critical stage of the habit; specifically, after initial cessation of substance use. In support of the relapse prevention model, Moos and Finney (1983) found that a significant portion of the variability associated with the long-term effectiveness of substance use treatment was related to environmental factors after completion of formal treatment. In addition, the relapse prevention model seeks to provide individuals with coping strategies to prevent a "slip" from progressing into a full-blown relapse. If these coping strategies are not developed and practiced, the model asserts that beliefs and expectations regarding a lapse may influence continued use (Moos \& Finney, 1983).

Throughout time and research, relapse prevention methods have been called into question regarding their efficacy (Irvin, Bowers, Dunn, \& Wang, 1999; Witkiewitz \& Marlatt, 2004). As a result, other treatment models for substance use and relapse being suggested (Drake, Wallach, \& McGovern, 2005; Witkiewitz, Marlatt, \& Walker, 2005) and tested (Bowen et al., 2009). To examine the relapse prevention model's efficacy, Irvin et al. (1999) conducted a meta analytic 
review of 26 studies to evaluate the effectiveness of Marlatt and Gordon's (1985) relapse prevention model in comparison to other active interventions (e.g., physician advice, psychoeducation). When compared to active interventions, relapse prevention was found to have few differences overall in comparison of effectiveness; additionally, the meta-analysis found that relapse prevention was less effective for some substances (e.g., cocaine use, cigarette smoking) (Irvin et al. 1999). Overall results indicated that relapse prevention was effective across substance of addiction, treatment setting, and in comparison to other treatment modalities (Irvin et al., 1999). However, it was found in the meta-analysis that relapse prevention had more of an effect in improving psychosocial functioning than on reducing substance use (Irvin et al., 1999).

Along with Irvin et al.’s (1999) calling the efficacy of relapse prevention into question, Witkiewitz and Marlatt's (2004) article proposed a reconceptualized cognitive-behavioral model of relapse that increases focus on the interactions between risk factors and situational determinants. In conjunction with Irvin et al.'s (1999) meta-analysis results, Witkiewitz and Marlatt (2004) provided literature supporting relapse prevention as more effective than no treatment and as equally effective as other treatment interventions (e.g., supportive therapy and interpersonal therapy). Along with their overview of relapse prevention effectiveness, the authors also suggested improving relapse prevention with a model that focuses on situational dynamics. Witkiewitz and Marlatt (2004) proposed future research in relapse prevention models to include self-efficacy, outcome expectancies, motivation, craving, coping, and emotional states variables. To supplement relapse prevention techniques, Witkiewitz and Marlatt (2004) suggested other treatments (e.g., mindfulness meditation) for addictive behaviors be implemented.

Accompanying the suggested improvements of relapse prevention (Irvin et al., 1999; Witkiewitz \& Marlatt, 2004), Drake et al. (2005) stated current approaches to relapse prevention 
emphasize cognitive aspects and minimize biological and socioenvironmental aspects. This minimization renders relapse prevention more effective for individuals without severe mental disorders. This suggests using the same relapse prevention model for individuals with and without severe mental disorders may be inadequate (Drake et al., 2005). The cognitive and social deficits in individuals with severe mental illness (e.g., brain reward systems, self-medication) can be expected to reduce the effectiveness of learning new skills and can lead to isolation and victimization. Therefore, these findings illustrate that general relapse prevention models are not effective across all populations that are treating substance use and need to be revised to provide efficacious treatment for individuals across different populations with differing needs.

Following Witkiewitz and Marlatt's (2004) suggestion of using an adjunctive treatment with relapse prevention, Witkiewitz et al. (2005) described a new approach to drug and alcohol addiction using Mindfulness-Based Relapse Prevention (MBRP). MBRP is implemented as an intervention combining mindfulness meditation with cognitive-behavioral skills training for addiction and is designed to reduce the risk and severity of relapse following substance use treatment (Bowen, Chawla, \& Marlatt, 2010; Witkiewitz et al., 2005). Witkiewitz et al. (2005) demonstrated that traditional relapse prevention is not effective for every individual with SUD. Witkiewitz et al. (2005) stated that little is known about the moderators and mediators of relapse prevention's effectiveness. It has been argued that there are cognitive (e.g., self-efficacy, craving, motivation) and behavioral mechanisms of change (e.g., contingencies, coping) that mediate and moderate the effectiveness of relapse prevention (Witkiewitz \& Marlatt, 2004) and that an underlying premise of these mechanisms is a focus on the present moment, acceptance, and nonjudgmental understanding (Witkiewitz et al., 2005). Mindfulness meditation is suggested to further enhance relapse prevention interventions for problematic substance use behavior based 
on the previously mentioned mechanisms that often go unaddressed. The goal of MBRP is to develop awareness and acceptance of thoughts, feelings, and sensations through practicing mindfulness as a way to cope with cravings and triggers for relapse (Witkiewitz et al., 2005). Bowen et al. (2009) conducted the first randomized controlled trial of MBRP and compared it to an outpatient 12-step relapse prevention program.

Bowen et al. (2009) assessed the treatment effects of MBRP on substance use outcome as well as associated processes such as craving, mindfulness, and acceptance. The authors hypothesized that participation in MBRP would be associated with greater reductions in substance use, and greater increases in acceptance and mindfulness compared to treatment as usual (Bowen et al., 2009). Treatment as usual was operationalized as a 12-step, process-oriented format that included topics of rational thinking skills, grief and loss, assertiveness, self-esteem, goal setting, and related themes. After an eight-week period of MBRP or a continuation of treatment as usual for eight weeks, participants then completed follow up assessments. Significant decreases were found in overall days of substance use, craving, and significant increases were found in levels of awareness and acceptance post-intervention among participants in the MBRP condition compared to participants in the treatment as usual condition (Bowen et al., 2009). However, these gains appeared to diminish four months after the interventions had concluded, returning to similar levels of the treatment as usual condition. This diminishment suggests further maintenance is required past an eight-week intervention to maintain levels of acceptance, awareness, and craving. Bowen et al. (2009) suggested the reduction in craving severity in their study may be explained by increased levels of awareness of sensations, thoughts, and emotions that accompany craving in combination with the encouragement of acceptance and nonreactivity to the craving response. The authors further discussed that with repeated exposure 
to craving triggering stimuli and the continued practice of nonreactivity, this may result in the forming of a habit over time, thereby decreasing the intensity of a craving sensation (Bowen et al., 2009).

To further add strength to the use of MBRP, recent research into this intervention (Bowen et al., 2014; Roos, Bowen, \& Witkiewitz, 2017; Witkiewitz, Bowen, Douglas, \& Hsu, 2013) has found effectiveness when compared to treatment as usual (Bowen et al., 2014) and has been associated with lower levels of craving (Witkiewitz et al., 2013). In addition, studies have found that MBRP is effective for preventing relapse in populations with severe SUDs and symptoms of depression and anxiety (Roos et al, 2017; Zemestani \& Ottaviani, 2016). Witkiewitz et al. (2013) examined the follow-up effects of MBRP on post-treatment craving scores and self-reported changes in craving during and following MBRP. Findings included that MBRP was associated with significant reduction in craving during and following MBRP (Witkiewitz et al., 2013). Specifically, the results showed that acceptance, awareness and nonjudgment significantly mediated the relationship between MBRP and self-reported levels of craving following the intervention (Witkiewitz et al., 2013). When compared to treatment as usual and cognitivebehavioral relapse prevention, MBRP has produced significantly lower relapse risk up to 12months posttreatment (Bowen et al., 2014).

Another example of MBRP and its efficacy in substance use relapse prevention is its use for individuals with dual diagnosis (Roos et al., 2017; Zemestani \& Ottaviani, 2016). Roos et al. (2017) compared the efficacy of MBRP to cognitive-behavioral relapse prevention models among participants recruited from a substance use treatment agency. Participants were assessed for substance use over a 12-month period, SUD symptom severity, and depression and anxiety symptoms. MBRP was found to have a significant main effect on participants with high SUD 
symptom severity, high depression, and anxiety symptoms (Roos et al., 2017). MBRP was also found to have a significant main effect on participants with high SUD symptoms severity, low depression, and anxiety symptoms in number of alcohol and drug use days (Roos et al., 2017). The results indicate MBRP may be more effective for clients with co-occurring high SUD symptom severity and high levels of depression and anxiety symptoms, and for clients with high SUD symptom severity and no presenting depression or anxiety symptomology (Roos et al., 2017). However, the findings also indicate that among clients with relatively less severe SUD symptoms, depression, and anxiety symptoms, there may be no significant differences in treatment effects with MBRP, cognitive-based relapse presentation, or treatment as usual (Roos et al., 2017), suggesting that other possible factors may be contributing to relapse occurrence, and that other treatments may be more effective for individuals with less severe pathology.

Similarly, Zemestani and Ottaviani (2016) investigated differences in reductions in cravings between participants in an inpatient setting receiving treatment as usual or MBRP. Participants receiving MBRP reported significant differences between pre- and post-treatment; specifically, differences were found through improvements in depression and anxiety symptoms, as well as craving symptoms when compared to participants in the treatment as usual condition (Zemestani \& Ottaviani, 2016). These findings are relevant due to the increased risk for relapse amongst depressed individuals with co-occurring substance use disorders (Brown et al., 1989; Uslaner et al., 1999), suggesting further factors related to depression may be contributory to relapse. Similar to Zemestani and Ottaviani’s (2016) research, Zgierska, Rabago, Chawla, Kushner, Koehler, and Marlatt (2009) found congruent results in their review of the existing literature on mindfulness-based interventions for SUDs. 
Zgierska et al. (2009) conducted a systematic review of the existing evidence on mindfulness-based interventions for SUDs. Overall, 50-85\% of the reviewed studies showed a positive outcome when mindfulness-based interventions were introduced to substance use affected subjects, compared to baseline conditions or other therapy. Additionally, data collected from controlled studies indicate that participants receiving mindfulness-based interventions do as well or better than participants receiving other therapy or pharmacotherapy alone in terms of maintaining sobriety (Zgierska et al., 2009). The current proposal intends to improve upon these methodologies by comparing the variance explained through mindfulness and other constructs in predicting substance use relapse amongst individuals recovering from SUDs.

Further strengthening the utility of mindfulness in the proposed study, Bowen et al. (2006) and Brewer et al. (2009) examined the use of mindfulness in reducing the amounts of substances used across different drugs. Bowen et al. (2006) found that the use of a mindfulnessbased treatment in an incarcerated population was related to reductions in alcohol, marijuana, and crack cocaine use. Additionally, Brewer et al. (2009) added feasibility to mindfulness training after comparing the practice to cognitive behavioral therapy in reducing stress reactivity in substance use patients. Their findings indicated that mindfulness training was just as effective in reducing stress reactivity as cognitive behavioral therapy in this specific population, indicating that these practices would promote abstinence and prevention of relapse. It is evident from the previously mentioned research that the trait of mindfulness is valued in the prevention of substance use relapse, but this literature also suggests there is room for other variables to be explored in their relation to substance use relapse. The current proposal aims to examine selfcompassion in its relation to relapse due to its relationship to mindfulness (Neff, 2003; 2004), and its inclusion of other cognitive and affective processes that have been found to be related to 
continued substance use (Brooks, Kay-Lambkin, Bowman, \& Childs, 2012; Miron et al., 2014; Rendon, 2007; Tanaka, Wekerle, Schmuch, Paglia-Boak, \& MAP Research Team, 2011; Vettese, Dyer, Li, \& Wekerle, 2011).

Relapse prevention has been found to have few differences overall in comparison of effectiveness to other treatment interventions (Irvin et al. 1999) but has been shown to be more effective than no treatment and equally as effective as other interventions (Witkiewitz \& Marlatt,2004). A separate relapse prevention intervention, MBRP, adds the component of mindfulness in the treatment of SUD and has been found to be associated with significant decreases in overall days of substance use and craving compared to treatment as usual (Bowen et al., 2009; Bowen et al., 2014; Witkiewitz et al., 2013). MBRP's utility in different populations has also been demonstrated in preventing relapse in populations with severe SUDs and symptoms of depression and anxiety (Roos et al, 2017; Zemestani \& Ottaviani, 2016). However, past research also suggests that other possible factors may be contributing to relapse occurrence, and that other treatments may be more effective for individuals with less severe pathology (Brown et al., 1989; Uslaner et al., 1999). The current proposal intends to improve upon these methodologies by comparing the variance explained through mindfulness and other constructs in predicting substance use relapse amongst individuals recovering from SUDs. The role of mindfulness in the process of relapse must be further examined before comparisons with other factors are made.

\section{Mindfulness}

A separate variable in the proposed research is trait mindfulness. There are varying definitions of mindfulness across research, but a common theme across all definitions is that mindfulness is a way of directing attention and being aware. Mindfulness is conceptualized as a 
state of consciousness integrating self-awareness and attention with personality characteristic of being open, welcome, and non-judgmental (Brown \& Ryan, 2003; Kabat-Zinn, 1990; Segal, Williams, \& Teasdale, 2002). Brown and Ryan (2003) defined mindfulness as also consisting of increased awareness and attention in present reality or current activity. Being mindful requires the awareness and focus on current experience, which involves concentrating on behavior that is out of conscious awareness (e.g., breathing) and attention (Kabat-Zinn, 1990; Segal et al., 2002). Brown and Ryan (2003) found that state mindfulness was positively associated with several dimensions of wellbeing (e.g., optimism, positive affect, self-actualization) and negatively associated with components of psychological and emotional disturbance (e.g., negative affect, depression, anxiety, rumination). Additionally, they found that state mindfulness predicted selfregulation and positive emotional states (Brown \& Ryan, 2003).

Mindfulness has also been examined in its relation to substance use and relapse (Appel \& Kim-Appel, 2009; Bowen \& Enkema, 2014; Fernandez, Wood, Stein, \& Rossi, 2010; Garland, Boettiger, Gaylord, Chanon, \& Howard, 2011; Garland, Roberts-Lewis, Kelley, Tronnier, \& Hanley, 2014; Karyadi \& Cyders, 2015; Leigh, Bowen, \& Marlatt, 2005; Leigh \& Neighbors, 2009; Robinson, Ladd, \& Anderson, 2014; Shorey, Anderson, \& Stuart, 2014; Shorey et al., 2013; Shorey, Brasfield, Anderson, \& Stuart, 2015). Throughout this past decade, mindfulness has been suggested to have a significant role in the development, treatment, and recovery from substance use and addiction, but research supporting this has been hampered by methodological issues and requires further study (Appel \& Kim-Appel, 2009). The construct of mindfulness has been presented with mixed findings in connection with substance use. In some studies, mindfulness has been found to be negatively related to alcohol use (Fernandez et al., 2010), severity of dependence (Bowen \& Enkema, 2014), and lifetime alcohol and marijuana use in 
clinical samples (Robinson et al., 2014); however, other studies found that mindfulness has been positively correlated with heavy substance use (Leigh et al., 2005; Leigh \& Neighbors, 2009). These mixed findings have led to the proposed study to further examine the prediction of relapse by trait mindfulness. The current proposal intends to add further study of the relationship between trait mindfulness, substance use, and addiction in a population of individuals recovering from SUDs.

Leigh et al. (2005) found a positive relationship between mindfulness scores and frequent binge-drinking behavior. Leigh and Neighbors (2009) followed up these findings by evaluating the mediating factors of coping and enhancement motives on the relationship between mindfulness and alcohol consumption among college students. They found that greater mind/body awareness was associated with more alcohol use in a non-clinical population of men and women (Leigh \& Neighbors, 2009). Contrasted with these positive associations of mindfulness and substance use behavior are findings of negative associations between mindfulness and substance use in clinical samples (Bowen \& Enkema, 2014; Fernandez et al., 2010; Robinson, Ladd, \& Anderson, 2014).

Fernandez et al. (2010) predicted mindfulness to be inversely related to both alcohol use and negative consequences due to alcohol in a population of 316 students at a mid-sized Northern public university. Through structural equation modeling, the authors found negative associations between alcohol use and the mindfulness sub-scales of "acting with awareness" and “describe" (Fernandez et al., 2010). Similarly, Robinson et al. (2014) found mindfulness to be negatively associated with a likelihood of lifetime alcohol or marijuana use. The aim of their study was to better understand the impact of mindfulness on substance use within the context of impulsivity. Baseline mindfulness was found to be a significant predictor of lifetime abstinence 
from marijuana and alcohol use in high school students (Robinson et al., 2014). The relatively low intensity of substance use within the sample limited the generalization of the results to individuals who use more heavily and use other substances, suggesting the relationship between mindfulness and substance use requires further examination. Bowen and Enkema (2014) sought to explore the relationship between substance use and mindfulness further by predicting a negative relationship between mindfulness and dependence severity in a clinical sample. Analyses assessed the relationship between trait mindfulness and severity of substance dependence in an adult clinical population, to provide further data on this relationship in clinical versus nonclinical populations. Results suggested a negative relationship between mindfulness and severity of dependence in treatment-seeking adults with SUD (Bowen \& Enkema, 2014). Further analyses of the subscales of the mindfulness measure revealed significant negative relationships between substance dependence severity and the mindfulness factors of acting with awareness, describing, and nonjudgment (Bowen \& Enkema, 2014).

Another example of inconsistent findings regarding the relationship between mindfulness and substance use is provided through a meta-analysis by Karyadi, VanderVeen, and Cyders (2014). The authors aimed to quantify the relationship between mindfulness and substance use behaviors, and to examine how the relationship varies across mindfulness facets and substance type. Potential moderators of the relationship were also examined in exploratory analyses and included sample characteristics (e.g., clinical status, gender, age, and race) and substance use severity (e.g., problematic vs. non-problematic substance use behaviors). A small but significant negative correlation was found in the relationship between mindfulness and substance use behaviors; however, this relationship varied across substance used, clinical status of participants, and substance use severity (Karyadi et al., 2014). Exploratory results indicated a more robust 
negative relationship between mindfulness and substance use for alcohol use and tobacco use disorders, problematic SUDs, and with inpatient clinical samples (Karyadi et al., 2014). The results of this conflicting research indicate further examination of mindfulness in relation to substance use needs to be continued along with its relationship to substance use relapse. The relapse prevention models that have been previously mentioned need to be specific in the treatment of substance use and maintenance of abstinence, but also need to be broadened to capture the entire SUD population, which implies that more variables need to be considered in relapse prevention such as trait mindfulness.

Kiken, Garland, Bluth, Palsson, and Gaylord (2015) defines trait mindfulness as one's predisposition to be mindful in daily life. Deepening the examination of the association between trait mindfulness and substance use, Garland et al. (2011) hypothesized that alcohol dependent individuals with higher levels of trait mindfulness would possess less attentional bias toward visual cues of alcohol compared to individuals with lesser levels of trait mindfulness. Trait mindfulness was found to be inversely associated with alcohol attentional bias, perceived stress, and subjective alcohol craving among individuals recovering from alcoholism (Garland et al., 2011). These results can be taken to mean that trait mindfulness relates to the disengagement of attention from alcohol cues, strengthening resistance against alcohol relapse and dependence. Repetitively engaging, disengaging, and moving attention away from alcohol cues towards beneficial stimuli is suggested to weaken associative networks of alcohol use action schemas and strengthen an alcohol dependent person's ability to avoid relapse (Garland et al., 2011).

Although these results provide insight into how trait mindfulness plays a role in refraining from substance use or relapse, it is necessary to inquire if trait mindfulness also plays a role into whether an individual seeks substance use treatment. An example of this additional 
role of trait mindfulness is provided through Shorey et al. (2013) and their examination of differences in trait mindfulness between adult substance users who sought residential treatment and in healthy, non-clinical adults. Greater deficits were found in individuals with substance users disorders seeking treatment compared to healthy adults in terms of trait mindfulness (Shorey et al., 2013). Specifically, individuals seeking treatment were found to have deficits in the trait mindfulness factors of curiosity and decentering as compared to healthy adults. Since the participants in the Shorey et al. (2013) study seem to be engaging in more healthy stimuli by seeking substance use treatment, but have deficits in certain areas of trait mindfulness, these findings are somewhat contradictory to Garland et al. (2011). Further research is needed to examine levels of trait mindfulness in those maintaining abstinence and those at high risk for relapse.

Specific factors of trait mindfulness have been found to be associated with various factors of substance use (Bowen \& Enkema, 2014; Fernandez et al., 2010; Garland et al., 2011; Shorey et al., 2013), but further research is mentioned linking mindfulness to specific factors of relapse such as craving (Garland et al., 2014) and maladaptive schemas (Shorey, Anderson et al., 2015; Shorey, Brasfield, et al., 2015). Garland et al. (2014) explored the possible mediators of the relationship between trait mindfulness and substance craving. Substance craving is defined as a sense of dysphoria or anxiety coupled with unpleasant somatic sensations that may impel an individual with a SUD to engage in substance use as a means of satiating the craving (Garland et al., 2014). First an inverted relationship was found between trait mindfulness and substance craving that was partially mediated by negative affect and reappraisal (Garland et al., 2014). These findings suggest that individuals in recovery from SUDs that possess higher levels of trait mindfulness may be less vulnerable to cravings because they are better able to downregulate 
distressing emotions and reappraise the meaning of life's challenges. Mindfulness is associated with craving in substance relapse, while additional research (Anderson et al., 2015; Shorey, Brasfield, et al., 2015) has found mindfulness to be related to a separate factor of relapse, maladaptive schema.

Shorey, Brasfield, et al. (2014) stated that substance use may be a form of avoidant behavior to cope with the remains of early maladaptive schemata. Since this relationship has been established, the authors examined the relationship between early maladaptive schemas and trait mindfulness in a sample of men seeking substance use treatment. They hypothesized that trait mindfulness would be negatively associated with early maladaptive schemas, and individuals who endorsed multiple maladaptive schemata would report lower trait mindfulness compared to individuals who endorse fewer early maladaptive schemata (Shorey, Brasfield, et al., 2015). The findings indicated that the majority of maladaptive schemata were negatively associated with trait mindfulness. The researchers also found that individuals who endorsed multiple maladaptive schemata evidenced lower levels of trait mindfulness compared to individuals with one or no early maladaptive schemata (Shorey, Brasfield, et al., 2015). Thus, the presence of early maladaptive schemata likely represents a lack of ability to be present and centered due to increased interactions between negative cognitive beliefs and maladaptive behaviors such as substance use. These findings are consistent with other research involving the maladaptive schemata factors of substance use and trait mindfulness.

For example, Shorey, Anderson, et al. (2015) also examined the relationship between trait mindfulness and early maladaptive schemata in a sample of women in residential substance use treatment. Like Shorey, Brasfield, et al. (2015), Shorey, Anderson, et al. (2015) hypothesized that trait mindfulness would be negatively associated with early maladaptive schema and that 
individuals with greater maladaptive schema endorsement would report lower trait mindfulness compared to individuals with less early maladaptive schema endorsement. Findings demonstrated that the majority of early maladaptive schemata were negatively associated with trait mindfulness in the sample of women seeking substance use treatment (Shorey, Anderson, et al., 2015). The findings also confirmed the authors' second hypothesis, that women with more than one early maladaptive schema reported lower trait mindfulness than women with one or no maladaptive schemata (Shorey, Anderson, et al., 2015). These combined findings represent a distinct factor of substance use that could be targeted in treatment to reduce the risk of relapse using the skill of mindfulness.

Further supporting the relationship between trait mindfulness and other factors contributing to substance use relapse, Karyadi and Cyders (2015) narrowed the scope in their examination of the relationship between trait mindfulness, alcohol cravings, and alcohol use behaviors. Specifically, the authors examined how trait mindfulness and its facets differentially related to separate alcohol use behaviors and how the relationships between trait mindfulness and alcohol use behaviors might be mediated by cued alcohol cravings (Karyadi \& Cyders, 2015). Trait mindfulness was found to be negatively associated with only problematic alcohol use, but not with alcohol quantity or duration of use (Karyadi \& Cyders, 2015). Additionally, cued alcohol cravings were found to be supported as the possible mechanism through which trait mindfulness and acting with awareness influence alcohol use (Karyadi \& Cyders, 2015). This suggests that individuals who specifically have higher levels of acting with awareness stand to be at lower risk for developing problematic levels of alcohol use by reducing the effect of alcohol cues on alcohol cravings. 
Taken together, mindfulness has been positively associated with several dimensions of well-being and negatively associated with components of psychological and emotional disturbance (Brown \& Ryan, 2003). Specifically, mindfulness has been found to be related to alcohol use (Fernandez et al., 2010), severity of dependence (Bowen \& Enkema, 2014), and lifetime alcohol and marijuana use in clinical samples (Robinson et al., 2014), but with mixed results (Bowen \& Enkema, 2014; Fernandez et al., 2010; Karyardi et al., 2014; Leigh et al., 2005; Leigh \& Neighbors, 2009; Robinson et al., 2014). The trait of mindfulness has also been found to be in deficit for individuals seeking substance use treatment (Shorey et al., 2013) and has been linked to specific factors of relapse such as craving (Garland et al., 2014), maladaptive schemas (Shorey, Anderson et al., 2015; Shorey, Brasfield, et al., 2015), and problematic use (Karyadi \& Cyders, 2015). However, further research is needed to examine differences in trait mindfulness for those maintaining abstinence and for those at more risk for relapse and to address other possible factors of substance use and relapse that are underrepresented in the variability explained by trait mindfulness. In efforts to better understand the process of substance use relapse, mindfulness and other personal factors need to be compared to one another in their predictability of relapse, such as self-compassion and self-efficacy.

\section{Self-Compassion}

The conceptualization of self-compassion can be rooted to Buddhist philosophy and has been used to better understand the development of healthy self-attitudes (Leary et al., 2007; Neff, 2003; Neff 2004). Neff (2003) defined and examined self-compassion in relation to other psychological constructs (e.g., coping, emotion regulation, mental well-being, self-esteem, selfpity) and linked the concept to overall psychological functioning. Self-compassion involves being open to one's own suffering, building the desire to relieve one's suffering, and healing 
oneself with kindness (Neff, 2003). Neff (2003) broke down self-compassion into three separate components: a) self-kindness, b) common humanity, and c) mindfulness. Self-kindness is defined as the extension of kindness and understanding to oneself rather than harsh judgement and selfcriticism. Common humanity is defined as seeing one's experiences as part of the larger human experience rather than perceiving these events as separating and isolating. The third component of mindfulness is defined as holding one's own painful thoughts and feelings in balanced awareness rather than over-identifying with them. Although substantial research has been done examining the relationship between self-compassion and substance use (Miron et al., 2014; Tanaka, Wekerle, Schmuch, Paglia-Boak, \& MAP Research Team, 2011; Vettese, Dyer, Li, \& Wekerle, 2011), and self-compassion's correlation with levels of depression, anxiety, and substance use (Brooks, Kay-Lambkin, Bowman, \& Childs, 2012; Rendon, 2007), the value of self-compassion in predicting substance use relapse has not been extensively studied or compared with other valuable predictors.

The construct of self-compassion was introduced in efforts to better define the concept of a healthy relationship and attitude with oneself. Although previous research has indicated that self-efficacy is an optimal measure for such a relationship (El et al., 2004; Ramo et al., 2005), an alternative concept possibly better suited for the population of substance users is selfcompassion. The population of individuals in recovery from substance use disorders has exhibited hatred and negative attitudes toward themselves, leading to more frequent relapse behaviors (Brown et al., 1989; Ulsaner et al., 1999). These findings open the possibility of selfcompassion being a beneficial area of development within the process of recovery for those suffering from substance use. 
The examination of self-compassion is differentiated from self-pity in that when a person experiences self-pity, the person becomes consumed with their own problems and forgets that others are experiencing similar issues; self-compassion allows one to see their relatable experiences and others' experiences without the disconnection (Neff, 2003). In a separate overview of self-compassion by Neff (2004), a distinction was made between self-compassion and self-esteem. Self-esteem is defined as our sense of self-worth, perceived value, or how much we like ourselves, whereas Neff (2004) stated that self-compassion is not based on selfevaluations or set standards. Within self-esteem, people feel love and kindness toward themselves based on traits or talents, compared to feeling love and kindness because they are human beings deserving of such compassion. Neff (2004) later reviewed research that has linked self-compassion to other indicators of healthy psychological functioning. Neff has previously found high levels of self-compassion to be associated with lower levels of neuroticism, anxiety, depression, rumination, and greater life satisfaction (Neff, 2004). Neff, Kirkpatrick, and Dejitthirat (2004) found self-compassion to be positively associated with problem-focused coping strategies and adaptive emotion-focused strategies, such as reframing one's issues in a positive manner, while also being negatively associated with maladaptive coping strategies, such as denial (as cited in Neff, 2004). Leary et al. (2007) also examined how people with low vs. high self-compassion respond to negative events. The five studies summarized consisted of 523 undergraduate college students reporting negative events in their daily lives, responding to hypothetical scenarios, reacting to interpersonal feedback, providing ratings of their or others' videotaped performances in an awkward situation, and reflecting on negative personal experiences. Participants high in self-compassion were more likely to accept responsibility for their role in negative events in their daily lives and attribute the cause of these negative events to 
the type of person they were (Leary et al., 2007). Self-compassionate people were less likely to ruminate on their negative evaluations by others and less likely to ruminate on their negative affect when confronted by their transgressions (Leary et al., 2007). These findings are taken together to "suggest that self-compassionate people more readily accept undesirable aspects of their character and behavior than people low in self-compassion without obsessing about them, becoming defensive, or feeling badly" (Leary et al., 2007, p. 901). From the examinations of self-compassion, it is evident that this concept is definable, measurable, and linked to several factors associated with healthy psychological functioning.

Self-esteem was further distinguished from self-compassion by how people react to negative events in daily life. Participants high in self-esteem responded to negative events in their daily lives with more defensiveness, rumination, and negative affect compared to participants high in self-compassion (Leary et al., 2007). These results provide further validity to the construct of self-compassion. Additionally, correlations between factors of psychological well-being and self-compassion, and predictive value of more positive cognitions following negative events, strengthen the validity of the construct. However, there is little research demonstrated for self-compassion to be predictive of positive outcomes in clinical populations recovering from substance use disorders, therefore leaving an avenue for self-compassion research to be conducted.

When recovering from addiction, a sense of motivation for abstinence must be present. Depression is reported to be at high levels within recovery and relapse (Uslaner et al., 1999), along with motivation being simultaneously reported to be low in both recovery and relapse. In relation to self-compassion, Breines and Chen (2012) concluded that if an individual performs practices of self-compassion, they will have a greater drive to improve their personal weaknesses 
or moral transgressions. These results can be broadened into the population of recovering substance use addicts; specifically, higher levels of self-compassion can increase the drive to improve the longevity of abstinence from illicit substances. A gap in the literature exists as to what internal characteristic can lessen the maladaptive processes that lead to relapse, thereby forming a research question asking if self-compassion a predictor of substance use relapse risk and be developed of strengthened to increase chances of sustained recovery. To strengthen the plausibility of using self-compassion to predict substance abuse relapse risk, characterizations of relapse must be shown to be negatively associated with self-compassion.

Substance use relapse can be a continuous cycle that is characterized by interpersonal conflict (Ramo et al., 2005) and urges or temptations (El et al., 2004). Perhaps a method of preventing relapse is treating the stepping stones to relapse rather than just treating the general problem of addiction. Self-compassion has been introduced as an intervention to reduce interpersonal conflict (Yarnell \& Neff, 2013). The authors hypothesized that individuals higher in self-compassion are more likely to compromise their personal needs when conflicts occurred in their relationships. College students were recruited to write a real-life example of a conflict they had with either their father, mother, best friend, or romantic partner. Afterwards, the 506 participants completed an emotional turmoil rating for the conflict and an assessment of wellbeing within the relationship context. Finally, participants were assessed on their levels of selfcompassion. The hypotheses were supported across the four relational contexts of mother, father, best friend, and romantic partner. Self-compassionate individuals were more likely to resolve their relationship conflicts in a manner that balances the needs of themselves and the needs of others (Yarnell \& Neff, 2013). This means that people higher in self-compassion were 
significantly more likely to resolve relational conflicts rather than lessen their personal needs or to assert priority of their needs over others (Yarnell \& Neff, 2013).

In terms of substance use and self-compassion's association, self-compassion has been found to be negatively associated with maltreatment backgrounds (e.g., child abuse), while these backgrounds were found to be positively associated with alcohol problems in the same results (Miron et al., 2014). Similar research has also found that adolescents with low self-compassion were more likely to experience alcohol use problems and other maltreatment-related impairments compared to adolescents with higher self-compassion (Tanaka et al., 2011). Finally, Vettese et al. (2011) found that participants' self-compassion levels were significantly and uniquely predictive of addiction severity. Although these results derive relationships among self-compassion, likelihood of developing substance use problems, and addiction severity, no further analyses or speculations are made of the directionality of the relationship between specific variables related to substance use.

In summarizing the literature relating self-compassion to substance use, it has been found that self-compassion is positively associated with positive coping strategies, while also being negatively associated with maladaptive coping strategies (Neff et al., 2004). Individuals with high levels of self-compassion were more likely to accept responsibility for their role in negative events and less likely to ruminate on negative affect (Leary et al., 2007). Self-compassion has also been found to be linked to other factors associated with substance use, such as moral transgressions (Breines \& Chen, 2012) and reduction of interpersonal conflict (Yarnell \& Neff, 2013). Within research relating self-compassion and substance use specifically, it has been found to be negatively associated with maltreatment backgrounds which were previously positively associated with alcohol problems (Miron et al., 2014). Different levels of self-compassion have 
been found to be related to problematic alcohol use experiences (Tanaka et al., 2011) and addiction severity (Vettese et al., 2011). To date, little research has linked self-compassion to outcomes of recovery from substance use disorders. A gap in the literature that the current proposal intends to close is the existence of self-compassion's role in relapse risk when compared against other known factors (e.g., trait mindfulness, self-efficacy) that relate to relapse in substance use recovery.

\section{Self-Efficacy}

Self-efficacy is the final variable that will be considered in the proposed research. Selfefficacy has been established as a predictor of substance use relapse while contended against other predictor variables (Ilgen, McKellar, \& Moos, 2007; Ilgen, McKellar, \& Tiet, 2005; Ilgen, Tiet, Finney, \& Moos, 2006; Moos \& Moos, 2006; Trucco, Connery, Griffen, \& Greenfield, 2007). Albert Bandura conceptualized self-efficacy in 1977 and defined it as confidence in one's own abilities to achieve intended results (Bandura, 1977). Self-efficacy beliefs have been found to determine how people think, feel, motivate themselves and act in social settings. These beliefs produce diverse effects through the major processes of cognition, motivation, affect and selection (Bandura, 1993). Other research regarding self-efficacy has shown the influential power it has on thought patterns, actions, and emotional arousal (Bandura, 1982). Perceived self-efficacy has been shown to account for "changes in coping behavior influenced by level of physiological stress reactions, self-regulation of behavior, resignation and despondency to failure experiences, self-debilitating effects of proxy control and illusory inefficaciousness, achievement strivings, growth of intrinsic interest, career pursuits..." (Bandura, 1982, p. 122). This means that an individual with a higher perception of self-efficacy has less stress, higher self-regulation behaviors, less personalization of failures, higher frequencies of relinquishing control, higher 
acts of striving for achievement, internal interest, and pursuits of a career. However, research has indicated that self-efficacy and self-compassion are related and "because research on selfcompassion is relatively new, studies that examine the relationships between self-compassion and psychological variables such as self-efficacy... are needed" (Iskender, 2009, p. 713).

Although very little research has been conducted comparing the predictability among self-compassion, self-efficacy, and mindfulness, some researchers have argued that self-efficacy (Bandura, 1999; Burling, Reilly, Moltzen, \& Ziff, 1989; DiClemente, 1986), mindfulness (Bowen et al., 2006; Brewer et al., 2009; Leigh, Bowen, Marlatt, 2005), and self-compassion (Miron, et al., 2014; Tanaka, Wekerle, Schmuch, Paglia-Boak, \& MAP Research Team, 2011; Vettese, Dyer, Li, \& Wekerle, 2011) are connected to substance use. The connection between self-efficacy and substance use has mixed findings. Burling, Reilly, Moltzen, and Ziff (1989) found contrary findings to the literature at the time, with their results of self-efficacy levels being higher in abstainers than those who relapse in their substance use, but self-efficacy was not related to the rates of relapse in a follow-up interview. However, DiClemente (1986) found that self-efficacy evaluations predicted successful abstinence. DiClemente (1986) originally sought to explore the role of self-efficacy in the process of addictive behavior change, specifically the stages of maintenance and cessation for a variety of addictive behaviors such as smoking, alcoholism, and over-eating. The results of his exploration found that participants' self-efficacy evaluations demonstrated value in discriminating which participants were likely to experience a relapse and which participants were likely to succeed in sustaining sobriety (DiClemente, 1986). Although DiClemente's (1986) study provided support to the construct of self-efficacy having a role in substance use relapse, there was little exploration into whether these results varied for those with differing drug addictions. El et al. (2004) found participants with alcoholism had a 
higher mean rating of self-efficacy in high-risk relapse situations compared to participants with a heroin addiction. The differences in self-efficacy among persons addicted to alcohol or heroin were attributed to a variety of factors, including a negative evaluation by community increasing the sense of inferiority and humiliation, thereby leading to lower self-efficacy (El et al., 2004). The current proposal suggests there are other factors such as self-compassion that may account for this sense of inferiority and humiliation and can be utilized as an additional predictor to substance use relapse in those recovering from SUDs.

Since El et al.'s (2004) research has utilized self-efficacy in predicting relapse during high-risk situations, self-efficacy has also been utilized in efforts to predict abstinence one year after SUD treatment (Ilgen, McKellar, \& Tiet, 2005). Participants were administered a battery of measures after detoxification from abusing substances and prior to the beginning of treatment, discharge, and 1-year follow up from their SUD treatment. Among the measures of substance use and confidence in high-risk relapse situations, an additional measure of general self-efficacy for abstinence was included in the battery. Ilgen et al.'s (2005) results add significant mixed findings in the relationship between self-efficacy and relapse. Not every participant with high abstinence self-efficacy was abstinent from their drug of choice at the 1-year follow up (Ilgen et al., 2005). These findings also suggest that self-efficacy may not be as potent of a predictor of relapse and abstinence and indicates that other factors need to be considered in treatment when relapse occurs. They also suggest that there are several variables that are included in the process of relapse, and examining one predictor is not enough to account for total variance. Self-efficacy was also predicted to be a factor that interacts with therapeutic alliance in relation to 1-year alcohol use-disorder outcomes (Ilgen et al., 2006). Participants were 785 individuals with a diagnosis of alcohol use-disorder and were assessed on three separate occasions during their 
outpatient treatment at a substance use treatment facility. They were assessed on drinking behavior, alcohol abstinence self-efficacy, and working alliance. Ilgen et al. (2006) found that self-efficacy and a stronger therapeutic alliance predicted better 1-year alcohol related outcomes, specifically a larger percent of abstinent days in one year. Although this further provides strong evidence for the use of self-efficacy in predicting abstinence in alcohol use-disorder, Ilgen et al.'s (2006) findings also indicate there are possible and underlying or separate factors that are of benefit when predicting a relapse. The methodology also leaves out self-efficacy in predicting abstinence within populations with differing types of addiction, furthering the need for literature to be added that examines these unknown factors and relationships. The current proposal intends to explore self-efficacy's role in the maintenance of recovery not only amongst those with alcohol use disorder, but with other SUDs as well.

The relationship between self-efficacy and abstinence has also been examined. Ilgen et al. (2007) examined predictors of self-efficacy 12 months after discharge from a SUD treatment. The predictors included patient characteristics at baseline, frequency of alcohol or drug use, alcohol/drug problems, psychiatric symptoms, substance use-specific coping, and confidence in abstinence. Participants completed the battery of assessments at intake to SUD treatment and at 1-year follow-up. Self-efficacy was found to be a product of both patient-specific attributes and behaviors and experiences during treatment (Ilgen et al., 2007). No treatment orientation was associated with higher self-efficacy at the 1-year follow-up assessment, which indicates that selfefficacy is largely related to a combination of pre-existing cognitive and behavioral patterns and skills learned during the participants' treatment (Ilgen et al., 2007). These findings indicate that general treatment for SUDs influences a patient's self-efficacy rather than a specific treatment orientation (e.g., Alcoholics Anonymous, 12-Step, cognitive-behavioral, therapeutic 
community). Treatment was considered as exposure to specific factors uniquely associated with greater self-efficacy such as coping skills and stress-management (Ilgen et al., 2007). Additional factors uniquely associated with self-efficacy that would be able to better predict the risk of relapse need to be further examined to investigate possible missing factors that influence the relationship between substance abstinence and internal factors.

More recently, Kelly and Greene (2014) examined the predictive utility of self-efficacy on substance use outcome along with a contingent factor of motivation for sobriety, and the interaction between self-efficacy and motivation. Participants were assessed based on alcohol and other drug use, abstinence self-efficacy and motivation for recovery at baseline, end of treatment, and three, six, and 12 months post-discharge. Through hierarchical modeling Kelly and Greene (2014) found that each variable alone is an independent statistically significant and moderately strong predictor of substance use. Also, there was a significant relationship found among these variables, indicating that one variable is dependent on the other. Findings included that for patients high in self-efficacy, the level of an individual's motivation made a statistically significant difference to their outcome over time, with "lower motivation pulling down percent of days abstinent despite the high confidence" (Kelly \& Greene, 2014, p. 7). For patients low in self-efficacy, the level of motivation made a significant difference, with high motivation making a positive impact in percent of days abstinent (Kelly \& Greene, 2014). Taken together, these findings indicate that highly motivated patients may be able to maintain higher levels of abstinence more successfully than those with low motivation.

Much like the previous research mentioned regarding mindfulness and substance use, the literature regarding self-efficacy and substance use is mixed. When combined with other variables accounting for abstinence, self-efficacy has been found to predict successful abstinence 
(DiClemente, 1986; Ilgen et al., 2006), indicating other underlying factors have separate roles from self-efficacy when predicting a relapse. In contrast with these findings, high abstinence self-efficacy has not always been found to be predictive of abstinence itself (Burling et al., 1989; Ilgen et al., 2005) and that this variable is not always a powerful predictor of abstinence regardless of drug of choice (El et al., 2004). Due to these mixed findings, there is a current need for studies examining the association between self-efficacy and substance use relapse. Additional research is also needed to examine the relationships between self-efficacy and other psychological variables such as self-compassion (Iskender, 2009). Although mindfulness, selfcompassion, and self-efficacy have been found to be related to substance use and relapse, these constructs have not been examined together. The current proposal intends to broaden upon Kelly and Greene's (2014) research, in comparing self-compassion, self-efficacy, and mindfulness in predicting substance use relapse, using hierarchical modeling.

\section{Rationale}

Prior research demonstrates that relationships among mindfulness, self-efficacy, and substance use relapse do exist. However, mindfulness and self-efficacy have not been consistently found to be negatively associated with substance use relapse (Burling, Reilly, Moltzen, \& Ziff, 1989; Leigh, Bowan, \& Marlatee, 2005) and self-compassion has only been utilized to predict addiction severity rather than relapse (Vettese et al., 2011), which raises the need for further research. The purpose of the proposed study is to examine self-compassion, selfefficacy, and mindfulness and their association to substance use relapse. Four hypotheses will be tested in this dissertation. 


\section{Research Hypotheses}

Hypothesis 1: The relationship between self-compassion (Self-Compassion Scale-Short Form; SCS-SF) and substance use relapse risk (Advanced Warning of Relapse Measure; AWARE) will be significantly negatively correlated in a sample of individuals recovering from addiction. A Pearson Product-Moment correlation will be conducted to assess the relationship between SCS-SF scores and AWARE scores.

Hypothesis 2: The relationship between self-efficacy (Drug Avoidance Self Efficacy Scale; DASES) and substance use relapse risk (AWARE) will be significantly negatively correlated in a sample of individuals recovering from addiction. A Pearson Product-Moment correlation analysis will be conducted to assess the relationship between DASES scores and AWARE scores.

Hypothesis 3: The relationship between mindfulness (Five Facet Mindfulness Questionnaire - Short Form; FFMQ-SF) and substance use relapse risk (AWARE) will be significantly negatively correlated in a sample of individuals recovering from addiction. A Pearson Product-Moment correlation analysis will be conducted to assess the relationship between FFMQ-SF scores and AWARE scores.

Hypothesis 4: In addition to the variance explained in relapse risk (AWARE) by selfefficacy (DASES), and mindfulness (FFMQ-SF), there will be a positive impact and an incremental explanation of variance by self-compassion (SCS-SF) in a sample of individuals recovering from addiction. Participants who score lower levels of self-compassion, self-efficacy, and mindfulness will be predicted to have higher substance use relapse risk. A hierarchical multiple regression analysis will be conducted to assess the relationship between SCS-SF scores, 
DASES scores, FFMQ-SF scores, and AWARE scores. The covariate of amount of time in treatment will be included in the regression model. 


\section{CHAPTER 2: METHODS}

\section{Participants}

Participants in the current study consisted of individuals recovering from substance use disorders. A multiple regression analysis with one degree of freedom and three total predictors was entered into G*Power (Faul, Erdfelder, Buchner, \& Lang, 2009), indicating a minimum sample size of 77 participants to find an existing medium effect. The Institutional Review Board (IRB) was informed that the study would limit the sample size to a maximum of 100 participants, which is similar to previous research on this topic. Participants were recruited from outpatient substance use treatment services at Chestnut Ridge Center, Lakewood Center, the residential treatment program Center for Hope and Healing and the intensive outpatient program. All are WVU Medicine treatment programs. The sampling of participants was conducted using a purposive sampling method. Inclusion criteria of the proposed sample consisted of having a preexisting diagnosis of any varied substance use disorder and being at least 18 years of age. Participation was not restricted based on sexual orientation, race, or ethnicity. Exclusion criteria for participants included a diagnosis of a non-substance-based addiction (e.g., gambling, sex, video games), younger than the age of 18 , and not having a pre-existing diagnosis of a substance use disorder.

\section{Measures}

\section{Drug Avoidance Self-Efficacy Scale (DASES, Martin, Wilkinson, \& Poulos, 1995).}

For the current study, self-efficacy was measured in individuals recovering from substance use using the DASES (Martin et al., 1995; Appendix A). The DASES is a 16-item measure which assesses self-efficacy for addictive behaviors that is applicable to individuals engaged in both single substance use and poly-substance use. The measure uses a response scale from 1 (certainly 
no) to 9 (certainly yes). Higher scores indicate higher drug avoidance self-efficacy. Items 2, 4, 7 , $8,10,11,12$, and 16 are reverse coded. A total score is computed. A sample item from this measure includes "Imagine that a new job is starting tomorrow, you are going out with friends and expecting a good time. Could you resist the urge to celebrate with drugs??. This variable was used as a predictor variable.

Martin et al. (1995) examined the construct validity by exploring this via convergent and divergent validity. The researchers found a consistent pattern of convergent and discriminant validity among the DASES items. Convergent and discriminant validity were assessed by examining the association of pretreatment self-efficacy with 15 variables related to drug use severity and duration along with measures of personality factors. Self-efficacy to avoid relapse was most strongly associated with factors that could impact confidence to avoid drug use in the future, providing convergent validation. Discriminant validity was found through a lack of association with individual or personality factors. In terms of construct validity, it was evaluated on a subset of the sample and was found to be evident in significant correlations with existing measures of differential rates of changes in self-efficacy associated with two types of treatment, and with similar measures of drug use severity. The correlations ranged from .26 to .66, which were all statistically significant (Martin et al., 1995). Cronbach's alpha for the overall scale was .91 and was not been improved by deleting any of the 16 items. Split-half reliability was assessed using two separate types of analyses. Using the Spearman-Brown analysis, the split-half reliability was found to be .90 and using the Guttman analysis, the split-half reliability was found to be .87 (Martin et al., 1995). Cronbach's alpha for the current sample was 0.921 which is acceptable (Taber, 2017). 
Five Facet Mindfulness Questionnaire-Short Form (FFMQ-SF, Bohlmeijer, ten Klooster, Fledderus, Veehof, \& Bohlmeijer, 2011). Trait mindfulness in individuals recovering from substance use was assessed using the FFMQ-SF (Bohmeijer al., 2011; Appendix B). The FFMQ-SF is a 24-item measure which assesses the five facets of trait mindfulness: observing, describing, acting with awareness, non-judging, and nonreactivity to inner experience. The measure uses a Likert-response scale from 1 (never or very rarely true) to 5 (almost always or always true). Higher scores indicate higher mindfulness. Items 4, 5, 7, 8, 11, 12, 14, 17, 19, 22 , 23, and 24 are reverse scored. This measure yields a total score. A sample item from this measure includes "I'm good at finding the words to describe my feelings." This variable was used as a predictor variable.

Bohlmeijer et al. (2011) examined the content validity with confirmatory factor analyses and by relating the FFMQ to measures of psychological symptoms, well-being, experiential avoidance, and the personality factors neuroticism and openness to experience. Confirmatory factor analyses showed good model fit for a correlated five-factor structure of the FFMQSF. The replicability of the five-factor structure of the FFMQ-SF was confirmed in a separate sample of participants. Five-factor models of the FFMQ demonstrated acceptable fit, where the correlated five-factor model (Bohlmeijer et al., 2011). This finding confirms that the FFMQ measures five distinct but related aspects of mindfulness, which can also be considered facets of an overall mindfulness factor.

To demonstrate convergent and discriminant validity, Pearson correlation coefficients were calculated between FFMQ facets and other constructs (e.g., Acceptance and Action Questionnaire-II, NEO Five-Factor Inventory, Hospital Anxiety and Depression Scale, Center for Epidemiological Studies Depression Scale, Mental Health Continuum-Short Form), and were 
found to be moderately or strongly related (convergent validity) or weakly or not related (discriminant validity) to mindfulness (Bohlmeijer et al., 2011). Reliability of the FFMQ facets were assessed with Cronbach's alpha coefficients. All facets of the FFMQ demonstrated adequate internal consistency reliability, with alpha coefficients of .75 for non-reactivity to inner experience, .81 for observe, .83 for acting with awareness, .83 for non-judging of inner experience, and .87 for describing (Bohlmeijer et al., 2011). Additionally, the facets were moderately intercorrelated ( $r$ 's ranged from .15 to .41), indicating that the facets measure related, but sufficiently distinct, aspects of mindfulness. Cronbach's alpha for the current sample was .82, which is robust (Taber, 2017).

\section{Self-Compassion Scale-Short Form (SCS-SF, Raes, Pommier, Neff, \& Van Gucht,}

2011). Self-compassion in individuals recovering from substance use was assessed by using the SCS-SF (Raes et al., 2011; Appendix C). The SCS-SF is a 12-item measure shortened from the self-compassion scale (SCS; Neff, 2003) which assesses the kindness and understanding toward the self in instances of pain or failure rather than being self-critical; the perception of one's experiences as part of the larger human experience rather than seeing them as unique to the self; and the possession of painful thoughts and feelings in mindful awareness rather than overidentifying with the maladaptive thoughts. The measure uses a Likert-response scale ranging from 1 (almost never) to 5 (almost always). Higher scores indicate higher levels of selfcompassion. Items 1, 4, 8, 9, 11, and 12 are reverse scored. Raes et al. (2011) examined the internal consistency reliability of the SCS-SF using a confirmatory factor analysis for each of the subscales. The confirmatory factor analysis demonstrated that the shortened SCS has the same higher-order factor structure as the original full scale with a 'general' higher-order selfcompassion factor and six second-order factors corresponding to the six facets of self- 
compassion: self-kindness, self-judgment, common humanity, isolation, mindfulness and overidentification. The internal consistency reliability coefficient for the SCS-SF total score is .86. The correlation between the total score of the long and short form was near perfect, $r=0.97$ (Raes et al, 2011). With these correlations and internal consistency estimates, it is reasonable to state the SCS-SF has good reliability (Raes et al., 2011).

Content validity of the original self-compassion scale (SCS) was examined by asking participants who they tended to be kinder to, themselves or others, expecting those with higher self-compassion would tend to say that they were equally kind to self and others, while those with low self-compassion would tend to say that they were kinder to others than to themselves. Within the assessment of content validity, convergent and divergent validity were assessed by including other established measures that assessed related constructs such as self-criticism, social connectedness, and emotional intelligence. To establish the content validity, individuals with higher self-compassion levels were found to be equally kind to the self and others, whereas individuals with lower self-compassion were found to be kinder to others than to themselves (Neff, 2003). With respect to the construct validity, self-compassion scores were found to have a significant negative correlation with the construct of self-criticism (-.65), and a significant positive correlation with the construct of social connectedness (.41). The results of these validity and reliability assessment studies support the validity and psychometric soundness of the SCSSF (Neff, 2003). A sample item from this measure includes, "I try to see my failings as part of the human condition." This measure yields on total score and was treated as a predictor variable. Cronbach's alpha for the current sample was 0.778, which is fairly high (Taber, 2017).

Advanced Warning of Relapse Scale (AWARE, Miller \& Harris, 2000). Relapse risk in individuals recovering from substance use disorders was assessed using the AWARE Scale 
(Miller \& Harris, 2000; Appendix D). The AWARE Scale is a 28-item measure that was designed as a measure of the warning signs of relapse. The measure uses a Likert-type response scale ranging from 1 (never) to 7 (always). The higher the score, the more warning signs of relapse are being reported. Items 8, 14, 20, 24, and 26 were reverse scored prior to computing participant total scores. A total score was yielded. A sample item from this measure includes "I think about using substances." Wording on items 1, 26, and 28 will be amended to apply to individuals that use alcohol and/or drugs. For example, item 1 states, "I feel nervous or unsure of my ability to stay sober." This item was amended to read "I feel nervous or unsure of my ability to stay clean of alcohol and/or drugs."

Miller and Harris (2000) examined the stability of scores over time of the AWARE by computing two indices of reliability. Internal consistency of the 28 -item scale was high at both baseline and 12 months with alpha coefficients of .91 and .93, respectively (Miller \& Harris, 2000). Test-retest reliability was also assessed to determine the stability of the AWARE scale over a two-month period. The test-retest correlation for the overall AWARE scale was .80 (Miller \& Harris, 2000). With these correlations and internal consistency ratings, it is reasonable to state the AWARE scale has good test-retest and internal consistency reliability. Predictive validity was examined by asking participants about their slip and relapse status at each follow-up point every two months post-treatment and were predicted by discriminant function analysis, entering first the client's drinking status at the prior interview. Then client's AWARE score from two months earlier was entered to determine whether the scale accounted for significant variance beyond that associated with prior drinking to demonstrate that AWARE still predicted both slip and relapse status at subsequent follow-up points. Harris and Miller (2000) found that AWARE scores still predicted both slip and relapse status. The AWARE scale has been found to have 
strong convergent validity with measures of symptom severity (Kelley, Hoeppner, Urbanoski, \& Slaymaker, 2011) and with measures of alcoholism and other measures designed to predict relapse (Harris \& Miller, 2000). Discriminant validity has been established by demonstrating a lack of statistically significant correlations with family substance use history, negative life experience, and motivation for change (all $r$ 's < 0.03) (Harris \& Miller, 2000). Only Pearson values of 0.40 or higher were reported (in this sample, $r=0.34$ would be the threshold for $p<$ .001 , which is the Bonferroni corrected alpha value). The results of these validity and reliability assessment studies support the validity and reliability of the AWARE scale. This variable was treated as a criterion variable. Cronbach's alpha for the current sample was 0.911 which is strong (Taber, 2017).

Substance Use Relapse and Demographics. A brief eight-item demographics questionnaire (Appendix E) was included in the measures. The demographics measured included the nominal variables of sex, race, and ethnicity, along with the continuous variable of instances having relapsed. Questions related to substance use relapse was also assessed within this same questionnaire. Assessment questions regarding substance use relapse included questions of drug of choice, number of times in substance use treatment, and number of times having relapsed on any substance in the past six months. The demographics questionnaire defined relapse as having sustained some days of sobriety prior to using an illicit substance or alcohol. These data were used as controls in the regression analyses.

\section{Procedures}

Following a full board review by the university's Institutional Review Board (IRB), participants were recruited from outpatient, group-based treatment programs for opioid use disorder using Medication Assisted Therapy (MAT) developed at West Virginia University as 
well as the Center for Hope and Healing, and an intensive outpatient program. Participants were recruited from the pre-existing, group-based treatment program using sampling methodology. To ensure the protection of the participants' rights, no identifying information was linked to their provided data. Participants were informed about their right to drop out of the study and their right to refuse to participate. Additionally, participants were informed about the duration of the study and the necessary instructions for completion of the battery of questionnaires. Each participant that agreed to participate in the study were rewarded one of $100 \$ 5.00$ Sheetz gift cards. If participants withdrew before the end of the study, they were not awarded a gift card. If participants successfully completed the study, they were awarded one of $100 \$ 5.00$ Sheetz gift cards, and it was given to them once they turn in the completed forms.

Upon entering a provided quiet room in each substance use clinic, participants were given recruitment (Appendix E) letters and informed consent forms (Appendix F) explaining their rights as participants in a psychological study, the right of refusal, an explanation of risks and possible discomfort, and an opportunity to withdraw their data without negative consequence. The primary researcher, and a Chestnut Ridge Center employed research assistant received consent only when the participant understood the procedures and when the participant signed the consent form. Once the consent process had been completed, the collection of data began with the administration of the questionnaire packet. The paper questionnaire packet along with a writing utensil was presented to each participant. The measures were distributed in random order (counterbalanced) to prevent order effects. The questionnaires provided included the SCS-SF (Neff, 2003b), the FFMQ-SF (Bohlmeijer et al., 2004), the DASES (Martin et al., 1995), the AWARE (Miller \& Harris, 2000) and finally a demographics questionnaire assessing substance use relapse. Each questionnaire was preceded with written instructions for completion. Once all 
questionnaires were completed, the participant was provided with post-study information regarding the nature of the study. The post-study information included a description of the study. Participants were informed that their contact information will not be linked to their responses to maintain the anonymity of their data.

\section{Design and Analysis}

Descriptive statistics were calculated, and data was assessed for normality prior to conducting the analyses. Data assessment for assumptions included obtaining an adequate sample size for four independent variables entered into the analysis. Also, the assumption of singularity was met as the independent variables (Drug Avoidance Self-Efficacy, Trait Mindfulness, and Self-Compassion) were not to be a combination of other independent variables. An examination of correlations was conducted to assess for an assumption of multicollinearity among independent variables. Other assumptions that were tested for normality of data included assumptions of normality, linearity, and homoscedasticity. If assumptions were not met, caution was expressed in the interpretation of significance and effect size. Descriptive statistics were then presented along with the internal consistency reliabilities for each of the instruments used. The first three hypotheses were tested using Pearson's $r$, the collected data from each participant's packet were analyzed through hierarchical multiple regression using the SPSS statistical package for Windows (I.B.M. Corp, 2010). The analysis specifically analyzed the magnitude and direction of the relationship between the variables of the explained variance in self-reported substance use relapse risk on the AWARE and among the three predictor variables of the FFMQ-SF, SCS-SF, and DASES. The hierarchical regression analysis was conducted by entering the constructs' total scores for each participant in a theoretical rank order based on previous literature for explaining the variance in the criterion variable of substance use relapse 
risk (AWARE). Models of comparison were made by adding variables to each previous model to compare the proportion of explained variance in substance use relapse rates. The covariate of amount of time in treatment was controlled in the regression model. Data were kept in a secure storage compartment under lock and key; data will be kept for five years after the completion of the study, and then it will be shredded and destroyed.

The current study was a descriptive correlational design with three predictor variables and one criterion variable. The predictor variables were self-compassion scores on the SCS-SF (Neff, 2003b), mindfulness scores on the FFMQ-SF (Bohlmeijer et al., 2004), and self-efficacy scores on the DASES (Martin et al., 1995). The criterion variable was substance use relapse risk, which was assessed using the AWARE (Miller \& Harris, 2000). Each participant's scores on the predictor variables served to predict the rate of participants' substance use relapse risks. The hierarchical regression analysis was conducted by the researcher entering in participant total scores on the DASES, FFMQ-SF, and SCS-SF in a theoretical rank order for explaining the variance in the criterion variable of substance use relapse measured by the AWARE construct. Models of comparison were made by adding variables to each previous model to compare the proportion of explained variance in substance use relapse rates. The previously listed analyses were utilized for the following hypotheses:

Hypothesis 1: The relationship between self-compassion (SCS-SF) and substance use relapse risk (AWARE) will be significantly negatively correlated. Participants who score lower on self-compassion will have higher substance use relapse risk. A Pearson ProductMoment correlation will be conducted to assess the relationship between SCS-SF scores and AWARE scores. 
Hypothesis 2: The relationship between self-efficacy (DASES) and substance use relapse risk (AWARE) will be significantly negatively correlated. Participants who score lower on self-efficacy will have higher substance use relapse risk. A Pearson Product-Moment correlation analysis will be conducted to assess the relationship between DASES scores and AWARE scores.

Hypothesis 3: The relationship between mindfulness (FFMQ-SF) and substance use relapse risk (AWARE) will be significantly negatively correlated. Participants who score lower on mindfulness will have higher substance use relapse risk. A Pearson ProductMoment correlation analysis will be conducted to assess the relationship between FFMQSF scores and AWARE scores.

Hypothesis 4: Participants who score lower on self-compassion, self-efficacy, and mindfulness will have higher substance use relapse risk. A hierarchical multiple regression analysis will be conducted to assess the relationship between SCS-SF scores, DASES scores, FFMQ-SF scores, and AWARE scores. Variables will be entered based on previous literature on connected relationships between self-efficacy, mindfulness, and self-compassion in predicting substance use relapse risk. In line with previous research, the first model will include participant total scores on the DASES predicting participant total scores on the AWARE. Also, in line with previous research, a second model will include participant total scores on the DASES and the FFMQ-SF in explaining the variance in participant total scores on the AWARE. Finally, a third model will be created that will include participant total scores on the DASES, the FFMQ-SF, and the SCS-SF in explaining the variance in participant total scores on the AWARE. The covariate of amount of time in treatment will be included in the regression model. It is hypothesized 
that the difference in the proportion of explained variance between the second and third model will be statistically significant and the added variable of participant total scores on the SCS-SF will explain the variance in participant total scores on the AWARE beyond the variables in the second model.

\section{CHAPTER 3: RESULTS}

\section{Descriptive Statistics}

Data were collected from 87 participants. Ten participants failed to complete each questionnaire within the questionnaire packet; therefore 77 participants were included in the final analysis. A post-hoc power analysis was conducted where the total sample size of 77 participants, and three total predictors, for a medium effect size was entered into G*Power (Faul, Erdfelder, Buchner, \& Lang, 2009) and a power of 0.8 was maintained. Participants were recruited from group-based WVU Medicine treatment programs including outpatient substance use treatment services at Chestnut Ridge Center, Lakewood Center, the residential treatment program Center for Hope and Healing, and the intensive outpatient program.

The average age of the sample was 35.2 years, ranging from 19 to 62 . The average number of times participants reported being in substance use treatment was 4.6 times, ranging from one to 18 . The average number of times participants reported relapsing in the past six months was 8.1 times, ranging from 0 to 180 . The average number of days reported in their current substance use treatment recovery was 398.6 days, ranging from two to 3,650 days. In terms of household income, the average amount was 22,633.53 dollars ranging from zero to 130,000 dollars. Forty-four (50.6\%) participants self-identified as male, 42 (48.3\%) selfidentified as female, and one (1.1\%) self-identified as transgender male to female. The ethnic 
diversity of participants included six (7.04\%) participants identifying as African-American, one (1.2\%) participant identifying as Hispanic or Latino/a, 77 (89.5\%) participants identifying as Caucasian American or White, and two (2.3\%) participants identifying as Biracial or Multicultural American. Seven (8.0\%) participants identified their primary drug of choice as alcohol, six (6.9\%) participants as crack, 29 (33.3\%) participants as heroin, $18(20.7 \%)$ participants as methamphetamine, four $(4.6 \%)$ participants as cocaine, three $(3.4 \%)$ participants as amphetamines or "uppers", four (4.6\%) participants as benzodiazepines or "downers", four (4.6\%) participants as marijuana, and $12(13.8 \%)$ participants as other or "prescription pain killers". Finally, participants were asked about their frequency of attendance in their substance use treatment groups. One (1.3\%) participant reported attending substance use groups zero times in a week, 27 (34.6\%) participants reported attending daily, 30 (38.5\%) participants reported attending weekly, 15 (19.2\%) participants reported attending bi-weekly, five (6.4\%) participants reported attending multiple days per week. Tables three and four provide a visual representations of participant demographics.

\section{Table 3}

\section{Demographic Characteristics of Participants}

\begin{tabular}{lcc}
\hline \multicolumn{1}{c}{ Characteristic } & \multicolumn{2}{c}{ Full sample } \\
\cline { 2 - 3 } & $n$ & $\%$ \\
\hline Gender & 44 & 50.6 \\
Male & 42 & 48.3 \\
Female & 1 & 1.1 \\
Transgender M2F & & \\
Ethnic/Racial Identity & 6 & 7 \\
$\quad$ African American or Black & 1 & 1.2
\end{tabular}


Caucasian American or White

77

2

Biracial or Multicultural American

Primary Drug of Choice

Alcohol

Crack

Heroin

Methamphetamine

Cocaine

Amphetamines "Uppers"

Benzodiazepines "Downers"

Marijuana

Other

Frequency of Group Participation

None

Daily

Weekly

Bi-Weekly

Multiple Days Per Week
89.5

2.3

8

6.9

33.3

20.7

4.6

3.4

4.6

4.6

13.8

1.3

34.6

38.5

19.2

6.4

Note. $N=87$. Participants were on average 35.2 years old $(S D=8.6)$.

Table 4

Means and Standard Deviations for Demographic Characteristics

\begin{tabular}{lccccc}
\hline \multicolumn{1}{c}{ Characteristic } & $M$ & $M d n$ & Mode & $S D$ & Range \\
\hline Age & 35.2 & 34 & 29 & 8.6 & $19-62$ \\
Times in Treatment & 4.6 & 3 & 1 & 3.9 & $1-18$ \\
$\begin{array}{l}\text { Number of Relapses in } \\
\text { Past 6 Months }\end{array}$ & 8.1 & 2 & 0 & 23.2 & $0-180$ \\
$\begin{array}{l}\text { Current Treatment } \\
\text { Duration (Days) }\end{array}$ & 398.6 & 60 & 60 & 771 & $2-3650$ \\
Household Income & 22633.5 & 12000 & 0 & 28337.9 & $0-130000$ \\
\hline
\end{tabular}

\section{Primary Analyses}

H1: The relationship between self-compassion (Self-Compassion Scale-Short Form; SCS-SF)

and substance use relapse risk (Advanced Warning of Relapse Measure; AWARE) will be significantly negatively correlated in a sample of individuals recovering from addiction.

Participants who score lower levels of self-compassion will be predicted to have higher substance use relapse risk. 
Correlation coefficients are presented in Table One. For the first hypothesis, a Pearson's product-moment correlation was conducted to assess the relationship between relapse risk and self-compassion in individuals recovering from addiction. Preliminary analyses showed the relationship to be linear with both variables normally distributed, as assessed by Shapiro-Wilk's test $(p>.05)$, and there were no outliers. There was a statistically significant, moderate negative correlation between relapse risk and self-compassion, $r(79)=-.47, p<.001$, with selfcompassion explaining $22.1 \%$ of the variation in relapse risk. Therefore, we can reject the null hypothesis and accept the alternative hypothesis.

H2: The relationship between self-efficacy (Drug Avoidance Self Efficacy Scale; DASES) and substance use relapse risk (AWARE) will be significantly negatively correlated in a sample of individuals recovering from addiction. Participants who score lower levels of self-efficacy will be predicted to have higher substance use relapse risk.

For the second hypothesis, a Pearson's product-moment correlation was run to assess the relationship between relapse risk and self-efficacy in individuals recovering from addiction. Preliminary analyses showed the relationship to be non-linear with relapse risk being normally distributed, but self-efficacy scores deviated from a normal distribution as assessed by ShapiroWilk's test $(p=.04)$. There was a statistically significant, large negative correlation between relapse risk and self-efficacy, $r(78)=-.64, p<.001$, with self-efficacy explaining $41 \%$ of the variation in relapse risk. Since, this relationship was found to be non-linear, an additional Spearman's rank-order correlation for this non-parametric data was run to assess the relationship between relapse risk and self-efficacy in individuals recovering from addiction. There was a strong, negative correlation between relapse risk and self-efficacy, which was statistically 
significant $\left(r_{s}(78)=-.63, p<.001\right)$. Therefore, we can reject the null hypothesis and accept the alternative hypothesis.

H3: The relationship between mindfulness (Five Facet Mindfulness Questionnaire - Short Form; FFMQ-SF) and substance use relapse risk (AWARE) will be significantly negatively correlated in a sample of individuals recovering from addiction. Participants who score lower levels of mindfulness will be predicted to have higher substance use relapse risk.

For the third hypothesis, a Pearson's product-moment correlation was conducted to assess the relationship between relapse risk and trait mindfulness in individuals recovering from addiction. Preliminary analyses showed the relationship to be linear with both variables normally distributed, as assessed by Shapiro-Wilk's test $(p>.05)$, and there were no outliers. There was a statistically significant, large negative correlation between relapse risk and trait mindfulness, $r(78)=-.65, p<.001$, with trait mindfulness explaining $42 \%$ of the variation in relapse risk. Therefore, we can reject the null hypothesis and accept the alternative hypothesis.

H4: In addition to the variance explained in relapse risk (AWARE) by self-efficacy (DASES), and mindfulness (FFMQ-SF), there will be a positive impact and an incremental explanation of variance by self-compassion (SCS-SF) in a sample of individuals recovering from addiction. Participants who score lower levels of self-compassion, self-efficacy, and mindfulness will be predicted to have higher substance use relapse risk.

For the fourth hypothesis, a hierarchical multiple regression was conducted to determine if the addition of trait mindfulness and then of self-compassion improved the prediction of relapse risk over and above self-efficacy alone. See Table Two for full details on each regression model. There was evidence of linearity as assessed by partial regression plots and a plot of studentized residuals against the predicted values. There was evidence of independence of 
residuals, as assessed by a Durbin-Watson statistic of 1.629. This indicates that the observations in the data were not related or auto-correlated. Finally, there was evidence of homoscedasticity, as assessed by visual inspection of a plot of studentized residuals versus unstandardized predicted values. The presence of homoscedasticity indicates that all variables have the same finite variance. There was no evidence of multicollinearity, as assessed by tolerance values greater than 0.1 . The independent variables of self-efficacy, trait mindfulness, and selfcompassion were not highly correlated with each other which prevented misunderstanding of which predictor variable contributed to the variance explained in relapse risk. There were no studentized deleted residuals greater than \pm 3 standard deviations, no leverage values greater than 0.2, and values for Cook's distance above one. This indicates there were no significant outliers, high leverage points, or high influential points. There assumption of normality was met, as assessed by Q-Q Plot, which indicates that the number of minor influences or errors followed a normal distribution and the F- test was applicable. The full model of self-efficacy, trait mindfulness, and self-compassion to predict relapse risk (Model 3) was statistically significant, $R^{2}=.544, F(3,73)=28.977, p<.001 ;$ adjusted $R^{2}=.525$. The regression equation was: predicted relapse risk $=212.747+(-0.509 \times$ DASEStotal $)+(-0.855 \times$ FFMQSFtotal $)+(-$ $0.132 \times$ SCSSFtotal). With self-efficacy, the addition of trait mindfulness to the prediction of relapse risk (Model 2) led to a statistically significant increase in $R^{2}$ of $.127, F(2,74)=$ 43.865, $p<.001$; adjusted $R^{2}=.530$. The regression equation was: predicted relapse risk $=$ $212.571+(-0.519 \times$ DASEStotal $)+(-0.899 \times$ FFMQSF). Self-efficacy predicting relapse risk (Model 1) was statistically significant, $F(1,75)=53.379, p<.001$; adjusted $R^{2}=.408$. The addition of self-compassion to the prediction of relapse risk (Model 3) did not lead to a statistically significant increase with a $R^{2}$ value of $.001, F(3,73)=28.977, p=.675$. The 
regression equation was: predicted relapse risk $=174.502+(-0.867 \mathrm{x}$ DASEStotal $)$. These initial results called for an additional analysis to test of a mediation effect.

\section{Table 2}

Hierarchical Regression Results for Relapse Risk

\begin{tabular}{|c|c|c|c|c|c|c|c|}
\hline \multirow[t]{2}{*}{ Variable } & \multirow[t]{2}{*}{$B$} & \multicolumn{2}{|c|}{$95 \% \mathrm{CI}$ for $B$} & \multirow[t]{2}{*}{$S E B$} & \multirow[t]{2}{*}{$\beta$} & \multirow[t]{2}{*}{$R^{2}$} & \multirow[t]{2}{*}{$\Delta R^{2}$} \\
\hline & & $L L$ & $U L$ & & & & \\
\hline Step 1 & & & & & & .42 & $.42 * * *$ \\
\hline Constant & $174.50 * * *$ & 152.87 & 196.13 & 10.86 & & & \\
\hline Self-efficacy & $-.87 * * *$ & -1.10 & -.63 & 0.12 & $-.65 * * *$ & & \\
\hline Step 2 & & & & & & .54 & $.13 * * *$ \\
\hline Constant & $212.57 * * *$ & 187.03 & 238.11 & 12.82 & & & \\
\hline Self-efficacy & $-.52 * * *$ & -.78 & -.26 & 0.13 & $-.39 * * *$ & & \\
\hline Trait mindfulness & $-.90 * * *$ & -1.29 & -.50 & 0.20 & $-.44 * * *$ & & \\
\hline Step 3 & & & & & & .54 & .00 \\
\hline Constant & $212.75 * * *$ & 187.04 & 238.45 & 12.90 & & & \\
\hline Self-efficacy & $-.51 * * *$ & -.78 & -.24 & 0.13 & $-.38 * * *$ & & \\
\hline Trait mindfulness & $-.86 * * *$ & -1.30 & -.41 & 0.23 & $-.42 * * *$ & & \\
\hline Self-compassion & -.13 & -.76 & .49 & 0.31 & -.04 & & \\
\hline
\end{tabular}

Note. $\mathrm{CI}=$ confidence interval; $L L=$ lower limit; $U L=$ upper limit.

$* p<.05 . * * p<.01 . * * * p<.001$. 
Test of Mediation. Initial evidence for a mediating effect is observed in Table 5. In this step, the effect of self-compassion, which is significant in the other models, is no longer present when trait mindfulness is added to the model (i.e: $\beta=-.06 ; \mathrm{SE}=.33 ; p=.59$ ). This type of finding can suggest mediation is occurring (Baron \& Kenny, 1986). To test this possible mediation further, Table 6 displays the results of the Baron and Kenny (1986) four step method which was conducted. The first three steps of this method establish the zero-order relationships among the mediation model variables. In the fourth step mediation is demonstrated when, with the inclusion of the mediator variable into the regression model, the initial relationship between the main predictor variable and outcome variable is no longer significant (Baron \& Kenny, 1986). As seen in Table 6, when self-compassion and trait mindfulness were entered in the fourth model, the relation of trait mindfulness to relapse risk remained significant $(\beta=-.56 ; \mathrm{SE}=.22$; $p<.001)$ and the relation of self-compassion to relapse risk was no longer significant $(\beta=-.14$; $\mathrm{SE}=.34 ; p=.204)$. These findings suggest that trait mindfulness fully mediates the relationship between self-compassion and relapse risk. 
Figure 1

Mediation Model with Self-Compassion, Trait Mindfulness, and Relapse Risk

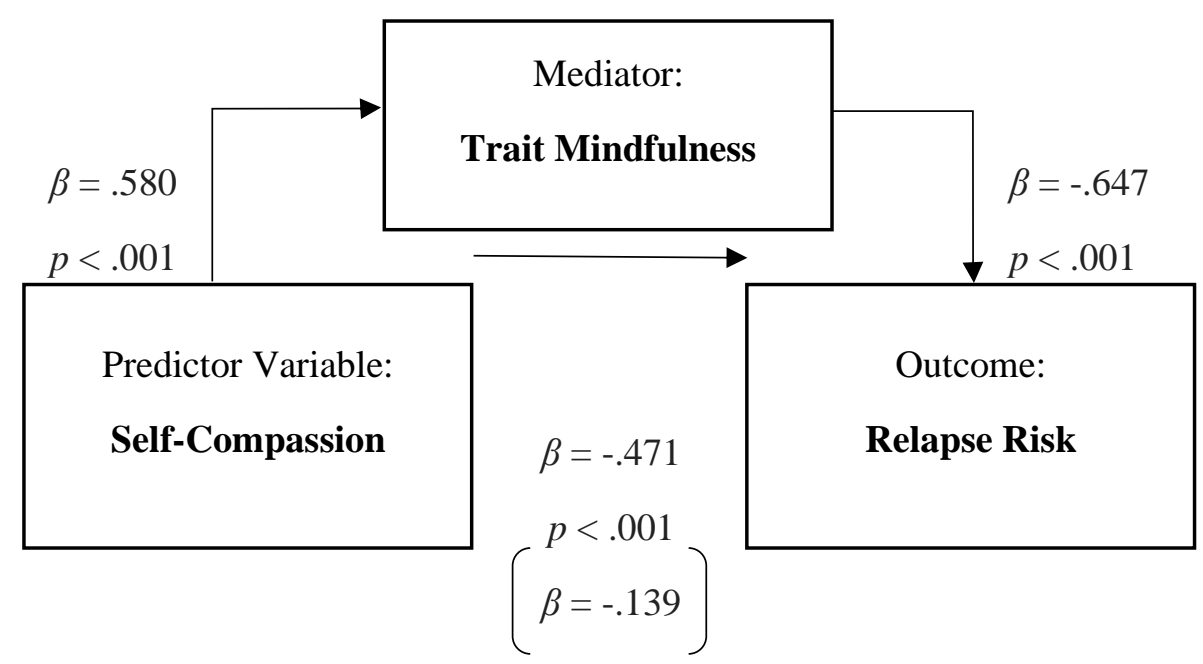

Figure 1. Model testing mediation of the relationship between self-compassion and relapse risk by trait mindfulness. Values in parentheses represent the standardized relation of selfcompassion to relapse risk after controlling for trait mindfulness. 


\section{Exploratory Analyses}

Group Differences. A one-way ANOVA was conducted to determine if self-efficacy (DASES), trait mindfulness (FFMQ-SF), self-compassion (SCS-SF), and relapse risk (AWARE) was different for groups with different primary substances of choice. Participants were classified into eight groups: alcohol $(n=7)$, crack $(n=6)$, heroine $(n=29)$, methamphetamine $(n=17)$, cocaine $(n=4)$, amphetamines "uppers" $(n=3)$, benzodiazepines "downers" $(n=4)$, marijuana $(n=4)$, and other (prescription opioids) $(n=12)$. The differences between these groups with different primary substances of choice were not statistically significant across self-efficacy, $F(8$, $77)=1.991, \mathrm{p}=.059$, trait mindfulness, $\mathrm{F}(8,76)=1.590, \mathrm{p}=.142$, self-compassion, $\mathrm{F}(8,77)=$ $0.978, \mathrm{p}=.460$, or relapse risk, $\mathrm{F}(8,70)=1.504, \mathrm{p}=.172$.

\section{CHAPTER 4: DISCUSSION}

\section{Summary of Findings}

The current study explored the relationships among self-efficacy, trait mindfulness, selfcompassion, and relapse risk in a sample of individuals enrolled in substance use recovery programs. Three of the four hypotheses indicated statistically significant results. Specifically, the findings indicated associations between relapse risk and self-compassion, relapse risk and selfefficacy, and relapse risk and trait mindfulness. The amount of variance explained in relapse risk by self-efficacy and mindfulness was not found to be statistically significant apart from the variance explained by self-compassion, thus not supporting the fourth hypothesis. However, after additional analyses, trait mindfulness was found to fully mediate the relationship between selfcompassion and relapse risk. This chapter will discuss the results of each analysis, possible 
explanations for the findings, strengths and limitations of the study, clinical implications, and future directions for research in this area.

\section{Explanation for Findings}

Hypothesis 1. Participant responses indicated a significant negative relationship between relapse risk and self-compassion, suggesting that greater levels of self-compassion are associated with lower levels of relapse risk in individuals recovering from substance use. Self-compassion is defined as a balance of cognitive and affective processes where individuals express kindness and understanding to themselves (Neff 2003b; 2016). Key components that have been associated with relapse in substance use recovery are feelings of failure, guilt, self-hatred, and self-blame (Uslaner et al., 1999) as well as negative affective states (Brown et al., 1989). If an individual recovering from substance use understands their condition and process while also evaluating their experiences nonjudgmentally and perceiving their experiences as shared with humanity, it makes sense that these self-compassionate individuals would be less likely to relapse. This finding is consistent with the little research that has explored this relationship (Tanaka et al., 2011; Vettese et al., 2011). Though the relationship between relapse risk and self-compassion was significant in this study, this novel finding is consistent with research investigating the relationship between substance use and self-compassion. This finding suggests that selfcompassion may be a useful intervention in therapy for those recovering from substance use disorders and to aid in relapse prevention. Previous literature supporting this relationship also suggests a negative correlational relationship between self-compassion and substance use disorders (Brooks et al., 2012) and a negative probability of developing a substance use disorder (Miron et al., 2014). 
The current result also adds support to previous findings regarding the relationship between the risk of using illicit substances and self-compassion (Vettese et al., 2011; Weiss et al., 2015). Although the association continues to be explored between self-compassion and relapse risk, further and more recent research continues to find consistent findings with that of the first hypothesis; specifically of an inverse relationship between substance use and selfcompassion (Phelps, Paniagua, Willcockson, \& Potter, 2018).

Hypothesis 2. Participant responses indicated a significant negative relationship between relapse risk and self-efficacy, suggesting that greater levels of self-efficacy are associated with lower levels of relapse risk in individuals recovering from substance use. Since high self-efficacy has been previously found in individuals with less stress, higher self-regulation behaviors, less personalization of failures, and higher acts of striving for achievement (Bandura, 1982), it is sensible as to why these individuals are less likely to relapse. The current study's finding is consistent with the self-efficacy literature that has supported its role in substance use relapse (Ilgen et al., 2007; Ilgen et al., 2006; Moos \& Moos, 2006; Trucco et al., 2007). This specific result also is contrary to the previous findings of self-efficacy having limited relation to relapse risk (Burling et al., 1989; Ilgen et al., 2005), which suggests that self-efficacy may be more of a potent predictor of relapse than previously thought. The current finding is also indicative of the length of abstinence from substance use. Much like Kelly and Greene's (2014) findings, current results suggest that self-efficacy can increase the length of abstinence in an individual's sobriety Only $8 \%$ of participants in the current study identified their drug of choice as alcohol, yet findings indicated that self-efficacy was negatively correlated to relapse risk regardless. This is contrary to previous literature, which indicated that self-efficacy was a factor for risk of relapse only in those whose drug of choice was alcohol (El et al., 2004). Perhaps a methodological 
shortcoming of El et al.'s (2004) study was the use of a self-efficacy measure that was not designed specifically for individuals recovering from substance use. The current study aimed to avoid this same limitation and used a measure that was designed to assess for level of selfefficacy in drug avoidance.

Hypothesis 3. Participant responses indicated a statistically significant negative relationship between trait mindfulness and relapse risk, such that greater levels of trait mindfulness are associated with lower levels of relapse risk. Trait mindfulness was originally defined as the propensity toward mindfulness in everyday life and consists of increased awareness and attention in present reality or current activity (Brown \& Ryan, 2003). Being mindful consists of being aware of and focusing on current experience, which involves concentrating on behavior that is typically out of conscious awareness and attention (Kabat-Zinn, 1990; Segal et al., 2002). Previous literature has found that mindfulness is positively associated with several dimensions of wellbeing and negatively associated with components of psychological and emotional disturbance as well as being predictive of self-regulation and positive emotional states (Brown \& Ryan, 2003). In order for individuals to successfully refrain from relapse, they must be able to be consciously aware of their recovery, their triggers, and their attitudes. This adds support to the previous findings of a negative association between trait mindfulness and substance use (Bowen \& Enkema, 2014; Fernandez et al., 2010; Robinson et al., 2014) while going against positive associations between trait mindfulness and substance use factors (Leigh et al., 2005; Leigh \& Neighbors, 2009). The current findings also provide support to the more specific relationship between trait mindfulness and relapse risk in substance use. Given this definition and the relationships with trait mindfulness, the current finding of the relationship between trait mindfulness and relapse risk is logical. 
Hypothesis 4. It was hypothesized that self-efficacy, trait mindfulness, and selfcompassion would predict relapse risk. Self-efficacy was found to be a significant predictor for relapse risk, and after adding trait mindfulness into the model, there was significantly more variance explained for relapse risk. After adding self-compassion into the model in combination with self-efficacy and trait mindfulness, the model was found to be still predictive of relapse risk; however, self-compassion did not add a significant amount of variance to the model. Given the previous literature regarding the relationships between self-efficacy and substance use (Ilgen et al., 2007; Ilgen et al., 2006; Moos \& Moos, 2006; Trucco et al., 2007), and trait mindfulness and substance use (Bowen \& Enkema, 2014; Fernandez et al., 2010; Robinson et al., 2014), it is understandable as to why these factors are further supported as potent predictors of substance use relapse risk. Although the current findings indicate self-compassion is negatively associated with relapse risk, the findings also suggest that self-compassion is not significantly different from self-efficacy and trait mindfulness in the prediction of relapse risk. The current finding also adds mixed results to Vettese et al.'s (2011) finding of self-compassion being predictive of addiction severity. However, when combined with self-efficacy and trait mindfulness, self-compassion may still be a valued component in substance use treatment in the prevention of relapse.

Additional analyses revealed that trait mindfulness fully mediated the significant relationship between self-compassion and relapse risk. This relationship suggests those in recovery from substance use need to possess a level of mindfulness (trait mindfulness) to develop a compassionate view of themselves (self-compassion) and thus, lead to a lesser risk of relapsing into substance use (risk of relapse). Ultimately, these findings shed light on the process in which mindfulness is an essential element of self-compassion while also informing the process in which an individual's level of self-compassion can be predictive of their risk of relapse into 
substance use. Results from the current study are consistent with previous literature (Garner, Gilbert, Shorey, Gordon, Moore \& Stuart, 2020; Phelps, Paniagua, Willcockson, \& Potter, 2018) and thus, support the notion that an individual's self-compassion is a powerful predictor of risk of relapse.

Exploratory Analyses. Further exploratory analyses were done to determine if selfefficacy (DASES), trait mindfulness (FFMQ-SF), self-compassion (SCS-SF), and relapse risk (AWARE) were different for groups with different primary substances of choice. Additional exploratory analyses were conducted to observe if a mediation effect was occurring by trait mindfulness mediating the relationship between self-compassion and relapse risk. No significant group differences were found between groups with differing primary substances of choice. Although no significant group differences were found within the current sample, future research is needed to determine if group differences exist amongst these variables and conducted with equal group sizes and a sufficient number of participants in each group.

\section{Implications of Findings}

Self-Efficacy in Substance Use Treatment. There are several implications that can be derived from the current study's results. First, self-efficacy was found to be negatively correlated with and predictive of relapse risk in individuals recovering from substance use. Previous research has found that self-efficacy was higher among abstainers than individuals who had relapsed, but it was not predictive of a positive treatment outcome (Burling et al., 1989). Other research has found self-efficacy evaluations to be predictive of successful abstinence (DiClemente, 1986) while Ilgen et al. (2005) found that self-efficacy was not always predictive of abstinence after a one-year follow-up. The implications of the current findings are consistent with the results reported by Burling et al. (1989) but leave the question of self-efficacy's ability 
to predict absence of relapse after a certain time unanswered. Future research is needed to add clarity to the question of self-efficacy being predictive of long-term recovery. It is also evident from the current findings that self-efficacy is not the only individual factor that is predictive of substance use relapse. Other factors such as trait mindfulness were found to add value in predicting relapse risk, which implies that self-efficacy is insufficient in its sole predictive value. In terms of substance use treatment, the current results imply that interventions designed to enhance self-efficacy must be present to some degree. Self-efficacy was predictive of relapse risk specifically in individuals recovering from substance use and seems to validate Witkiewitz and Marlatt's (2004) call for relapse prevention models to include self-efficacy. Bandura (1986) identified four principal sources of efficacy beliefs: performance attainments; vicarious experiences of observing the performance of others; verbal persuasion to try to convince people that they possess certain capabilities; and physiological states based on which people judge their capabilities, strengths, and vulnerabilities. If individuals recovering from substance use are taught coping skills (e.g., problem-solving, social skills, communication skills) and they directly experience success afterword because of implementing those skills, this perceived success is likely to enhance their efficacy beliefs and thus reduce the likelihood of relapse. The aspect of assigning homework practice exercises has been found to be supported in the enhancement of self-efficacy. Annis, Schober, and Kelly (1996) found that homework tailored to individuals' high-risk situations is beneficial for increasing self-efficacy. They identified six aspects of homework assignments that are expected to alter perceived efficacy, along the lines suggested by Bandura (1986): (1) the homework assignments must be challenging, (2) they should require a moderate degree of effort, (3) they should require little external aid, (4) success in the assignments should be perceived as part of a pattern of improved performance, (5) the 
assignments should increase the perception of personal control and decrease reliance on external supports, and (6) the assignments should be relevant to problem situations frequently encountered (Annis et al., 1996).

Curry and Marlatt (1987) also emphasized the importance of tailoring interventions aimed at enhancing self-efficacy and recommended keeping homework assignments simple, to maximize the likelihood of success and increase self-efficacy. Another method of enhancing the self-efficacy of substance abusing clients includes Motivational Interviewing (MI). Miller and Rollnick (2002) stated that "supporting self-efficacy" is one of the guiding principles of motivational interviewing. MI includes strategies that facilitate the development of self-efficacy, such as expressing confidence in the client's ability to change, reviewing past successes and current strengths, using the confidence ruler technique, presenting a number of change options, and developing explicit strategies for implementing changes (Miller \& Rollnick, 2002). The present research indicates that self-efficacy is an element that needs to be included in substance use treatment to have an effect on relapse risk. Previous research indicates that this factor can also be an element of change for individuals with substance use disorders vulnerable to relapse (Annis et al., 1996; Curry \& Marlatt, 1987; Miller \& Rollnick, 2002). Further research should include longitudinal results after implementing self-efficacy-enhancing methods in efforts to reduce the likelihood of relapse.

Mindfulness in Substance Use Treatment. The current findings also included the negative association between trait mindfulness and relapse risk. This implies that an individual recovering from substance use has an additional factor that plays a role in their relapse prevention. Although the causality of the relationship cannot be derived from the current results, a significant association exists between the two factors. In addition, trait mindfulness was found 
to explain a significant amount of variance in predicting relapse risk. This finding implies that mindfulness may play a more significant role in substance use treatment than previously thought. Previous research has found mindfulness to be deficient for individuals seeking substance use treatment (Shorey et al., 2013) and has been linked to specific factors of relapse such as craving (Garland et al., 2014), maladaptive schemas (Shorey, Anderson et al., 2015; Shorey, Brasfield, et al., 2015), and problematic use (Karyadi \& Cyders, 2015). The current finding of the negative association between trait mindfulness and relapse risk adds further clarity to the mixed results between these two factors (Leigh et al., 2005; Leigh \& Neighbors, 2009) and begins to answer a call for further research (Appel \& Kim-Appel, 2009).

A clinical implication of the current findings is further support of the utility of mindfulness-based relapse prevention (MBRP). Previous research has found significant decreases in overall days of substance use and craving post-MBRP treatment for individuals in recovery (Bowen et al., 2009). Significant increases found in levels of awareness and acceptance post-MBRP treatment were the positive effects for individuals recovering from substance use (Bowen et al., 2009). This treatment has been found to be effective in preventing relapse in populations with severe SUDs (Bowen et al., 2014; Roos et al, 2017; Zemestani \& Ottaviani, 2016). Within MBRP, identification of high-risk situations remains central to the treatment. Participants in MBRP are trained to recognize early warning signs for relapse, increase awareness of internal (i.e., emotional and cognitive) and external (i.e., situational) cues previously associated with substance use, develop effective coping skills, and enhance selfefficacy. Mindfulness practices included in MBRP are intended to raise awareness of triggers, monitor internal reactions, and foster more skillful behavioral choices. The practices focus on increasing acceptance and tolerance of positive and negative physical, emotional, and cognitive 
states such as craving, thereby decreasing the need to alleviate these negative affective states through relapse. The current findings also imply that trait mindfulness may be an efficient gauge for where individuals are in their recovery. For example, if an individual is found to have low trait mindfulness, it is logical to predict that the same individual's likelihood of relapse is high during that time, given the current results. As stated previously, trait mindfulness also introduces a separate intrinsic factor for change while in substance use treatment. If this component were one of few to be made central in substance use treatment using practices already supported in this population, such as MBRP, it is reasonable to conclude that the risk of relapse will be lower compared to treatments as usual that lack a mindfulness component. Future research should explore the longitudinal effects of MBRP in combination with self-efficacy practices; specifically, on the rate of relapse for individuals recovering from substance use.

Self-Compassion in Substance Use Treatment. The final significant finding of this study was the negative association between self-compassion and relapse risk. However, causality cannot be derived from the current results. We cannot determine if those who are at high risk of relapse begin to lose self-compassion, or if low self-compassion increases the risk of relapse. Previous research lends support to the notion of self-compassion being addressed while in substance use treatment, indicating that self-compassion may need to be included as a part of treatment for this population. Previous studies have found those in recovery from substance use disorders exhibit hatred and negative attitudes toward themselves, leading to more frequent relapse behaviors (Brown et al., 1989; Ulsaner et al., 1999). Neff’s (2003; 2004) concept of selfcompassion encourages the development of healthier self-attitudes that are meant to treat negative attitudes toward the self and promote more self-kindness and less critical self-judgment. Self-compassion has also been found to be positively associated with positive coping strategies 
and negatively associated with maladaptive coping strategies (Neff et al., 2004). In terms of substance use, previous research has found that self-compassion is predictive of addiction severity (Vettese et al., 2011), and until the current research, was not studied in its relationship to relapse risk. Although the current study was unable to derive a predictive relationship between the two variables, the correlational results imply that self-compassion-oriented treatments may have a place in substance use treatment.

Gilbert and Procter (2006) developed a self-compassion-oriented therapy called Compassionate Mind Training (CMT). This therapy was developed for individuals with high shame and self-criticism, and for those who find self-warmth and self-acceptance difficult. Compassionate Mind Training has been found to significantly reduce levels of depression, anxiety, self-criticism, shame, inferiority, and submissive behavior (Gilbert \& Procter, 2006). CMT has also been found to improve participants' abilities to be self-soothing and provide selfreassurance (Gilbert \& Procter, 2006).

An additional self-compassion-oriented treatment is Compassion Focused Therapy (CFT) (Gilbert, 2009). While CMT refers to specific activities designed to develop compassionate attributes and skills, particularly those that influence affect regulation, CFT refers to the underpinning theory and process of applying a compassion model to psychotherapy (Gilbert, 2009). The aim of CFT is to replace feelings of hostility and insecurity toward oneself with compassion and understanding, so that individuals can learn to soothe themselves, accept soothing from others, and generate feelings of contentment and safety. CFT is just beginning to be researched in terms of feasibility for those recovering from substance use, and results indicate that those with substance use disorders desire more CFT sessions and that it is feasible and welltolerated (Carlyle et al., 2019). However, CFT has only been implemented in populations with 
opioid use disorder, and future research should consider implementing this therapy with individuals recovering from any substance use disorder. Additionally, CFT has not been measured in terms of its effect on prolonged substance use relapse. Future research needs to determine the longitudinal effects of CFT on preventing relapse in those recovering from substance use. The current study collected data from individuals diagnosed with substance use disorders ranging across all types. Given that the current results were found within a population varying in substance use disorders, it is reasonable to believe CFT may benefit those in recovery from all or most substances.

A separate self-compassion-oriented treatment that has begun to be researched in treating those with substance use disorders is brief self-compassion training (BSCT). BSCT, developed by Held, Owens, Thomas, White, and Anderson (2018), was derived from practices used in other compassion-based interventions, such as mindful self-compassion (Neff \& Germer, 2013) and compassion-focused therapy (Gilbert \& Procter, 2006). Generally, BSCT relies on several cognitive-behavioral strategies to help participants change their perspectives. BSCT is a structured, four-session intervention that was designed to teach participants core self-compassion skills (Held et al., 2018). BSCT is delivered in a group format over the course of four weekly 60minute sessions. Participants learn and practice new self-compassion skills each week and are encouraged to complete homework assignments to further facilitate skills practice between sessions (Held et al., 2018). Pilot results of this program with individuals in substance use treatment programs include significant increases in self-compassion, emotional intelligence, and presence of meaning in life, and statistically significant decreases in trauma-related guilt and shame (Held et al., 2018). Much like research regarding CFT, little to no research has examined the effect of BSCT on relapse in substance use populations. Future research should assess the 
effect of this therapy on individuals recovering from substance use and their risk of relapse. The current findings imply that a relationship exists between self-compassion and relapse risk in individuals recovering from substance use; however, this is a novel discovery in the association of these two factors. Further research is needed to clarify this relationship and to derive effects of self-compassion-oriented therapies on the risk of relapse.

\section{Integrating the Three Treatments}

It is evident from the previous implications that each of the three tested variables plays a role in substance use relapse and can be utilized in various treatments. However, greater success in preventing substance use relapse could possibly be had when integrating the three treatment models (i.e., self-efficacy relapse prevention, MBRP, CFT). Integrated treatment models have been previously found to be superior to treatment of individual disorders with separate treatment plans (Kelly \& Daley, 2013). Elements that could be taken from self-efficacy-oriented treatment models include the teaching of coping skills (e.g., problem-solving, social skills, communication skills) and homework designed to increase self-efficacy (Annis et al., 1996). Additionally, the component of motivational interviewing would address the development of self-efficacy and explicit strategies for implementing changes (Miller \& Rollnick, 2002). Possible areas essential for the recovery from substance use and in the prevention of relapse would be addressed by these self-efficacy-enhancing treatment elements.

The elements found to reduce the likelihood of relapse from mindfulness-based interventions have been previously integrated with positive results (Bowen et al., 2009; Roos et al, 2017; Zemestani \& Ottaviani, 2016). An integrated treatment would focus on previouslyunaddressed areas of relapse such as craving (Garland et al., 2014), maladaptive schemas 
(Shorey, Anderson et al., 2015; Shorey, Brasfield, et al., 2015), problematic use (Karyadi \& Cyders, 2015) and prolong overall days of abstinence and decrease craving (Bowen et al., 2009). An example of an integrated model with elements of self-efficacy and mindfulness is MBRP; this model promotes identification of high-risk situations, recognition of early warning signs for relapse, increasing awareness of internal (i.e., emotional and cognitive) and external (i.e., situational) cues previously associated with substance use, developing effective coping skills, and enhancing self-efficacy. As previously mentioned, mindfulness may be an efficient gauge for where individuals are in their recovery, thereby providing an estimate for likelihood of relapse. This would introduce a new component to the self-efficacy-enhancing interventions.

Despite these areas of substance use relapse addressed, there remains an unaddressed area of self-attitudes as indicated by the current results. Previous self-compassion treatment models have been found to significantly reduce levels of depression, anxiety, self-criticism, shame, inferiority, and submissive behavior (Gilbert \& Procter, 2006) and facilitate the ability of individuals to soothe themselves, accept soothing from others, and generate feelings of contentment and safety (Gilbert, 2009). More recently, the self-compassion-oriented treatment model of BSCT with individuals in substance use treatment programs have resulted in significant increases in self-compassion, emotional intelligence, presence of meaning in life, and statistically significant decreases in trauma-related guilt and shame (Held et al., 2018). Based on the current findings and previous research concerning the effectiveness of these treatments for substance use, it is logical to conceive of an integrated treatment model that combines these elements to address the variability in relapse for those in recovery. Future research needs to examine the feasibility of combining these treatment orientations and address the effectiveness and the 
applicability to the substance use population. If positive results are found from this proposed integrated treatment, several measurements are needed to validate its use in relapse prevention.

\section{Strengths of the Study}

There are several strengths of the design of the current study. One strength pertains to the aim of the study; specifically, to fill gaps in the literature concerning self-efficacy (El et al., 2004), mindfulness (Bowen \& Enkema, 2014; Karyadi et al., 2014; Shorey et al., 2013), selfcompassion (Iskender, 2009; Vettese et al., 2011), and relapse risk (Ilgen et al., 2005; 2006) in the substance use population. The examination of associations between these four variables addresses gaps in the literature as well as provides further strength to previously-researched relationships with substance use and the less examined substance use variable of relapse risk.

A second strength of this study is the use of the AWARE (Miller \& Harris, 2000) as a measure of relapse risk. To date, very few studies have used this measure in relation to selfefficacy, mindfulness (Crescentini, Matiz, \& Fabbro, 2015), and self-compassion. This is important because the AWARE is one of the few well-validated measures of relapse risk without needing participants to engage in the process of relapse. Additionally, the AWARE measure was further validated in its use within the population of individuals recovering from substance use. Further, the present study also replicated results found in previous studies using the variables of mindfulness, self-efficacy, and self-compassion while also having found associations among these variables and the AWARE measure of relapse risk which is a novel association using this specific measure.

The method of data collection in the present study presents various strengths that are important to note. First, the current study collected data from the most relevant population for this research. Few studies outside of grant-funded research can access the substance use 
population. Most of the literature that examines these areas are assessed in college student populations or with small samples from the substance use population. In the current study, I worked diligently to ensure the data were collected from a population that was most expected to benefit from its results. In an effort to broaden results, data were collected from various sources including inpatient and outpatient clinical settings. To date, the present research is one of few studies that examine the relationships among these variables in a sample of individuals recovering from substance use disorders.

A separate strength of the data was its demographic breakdown and the resemblance it shows with the state demographics of West Virginia. The present study sampled individuals who were enrolled in either an inpatient or outpatient substance use treatment setting. The demographics in the present study reflected the following racial breakdown: $89.5 \%$ Caucasian American or White, 7.0\% African American or Black, 1.2\% Hispanic or Latino/a, 5.7\%, and $2.3 \%$ biracial or multicultural American. Unfortunately, the racial demographic data of individuals enrolled in substance use treatment is not known in the state of West Virginia. However, the most recent U.S. Census Data for West Virginia as of 2018 indicated the following racial breakdown of West Virginia citizens: 93.2\% White, 3.7\% Black or African American, $1.5 \%$ Hispanic, and $1.8 \%$ two or more races.

\section{Limitations and Future Directions}

Research design. Within the current study, there are various limitations that need to be addressed. Specifically, the chosen research design presents threats to both internal and external validity.

Threats to Internal Validity. The first three hypotheses are of a correlational research design which creates difficulty in determining causality between factors. Being that no variables 
were manipulated in this study, the direction of the association in the first three hypotheses were unclear. The purpose of using a correlational design for the first three hypotheses in this study was to clarify the respective relationships between self-efficacy and relapse risk, and trait mindfulness and relapse risk, as well as fill in the gap in the literature to determine whether a relationship exists between self-compassion and relapse risk. Future research needs to better determine causality using more complex research designs. Since the surveys in the current study were all self-report measures, this methodology also poses a separate limitation. Heppner, Wamphold, and Kivlighan (2008) explained that self-report methodology shares a common respondent bias, and it also does not allow for extensive validation or reliability of the results. Future directions of research should examine similar data from various sources including the individual recovering from substance use, their substance use counselor or therapist, and close family members. Measurement of these variables from various sources could add more reliability to the relationships and introduce the possibility for more complex analyses to be conducted.

A separate limitation to the current study is the accurate measurement of intended constructs. The measures chosen for this study included the AWARE, the DASES, the FFMQSF, and the SCS-SF. It is possible that different measures along with elongated forms of measures may have been better suited to assess for the hypothesized relationships. Specifically, the FFMQ conceptualized mindfulness as a multifaceted construct to help understand its components with other variables (Baer, Smith, Hopkins, Krietemeyer, \& Toney, 2006). The current study utilized a total score of the FFMQ rather than compare the various facets of mindfulness and their relationships with relapse risk. Future research should consider using the multiple facets offered on the FFMQ or the FFMQ-SF to fully understand the specific associations mindfulness has with relapse risk. 
An additional issue in accuracy of measurement was the use of the SCS-SF. In the current study, the SCS-SF was used for testing convenience and prevent participants from becoming test fatigued. However, the current results revealed that participant responses on the SCS-SF did not account for significantly more variance in relapse risk than did participant responses on the DASES and the FFMQ-SF. Perhaps, using the full form of the SCS (Neff, 2003) would have added more data to the current hypotheses. Raes et al. (2011) noted that the short form of the SCS has less reliability in terms of the subscale scores and recommended using the full form of the SCS if interested in these scores. In future research, the subscale scores of the SCS should be investigated in their association with relapse risk in efforts to possibly narrow down treatment to a specific component of self-compassion.

The use of the DASES in the current study also is a concern for accuracy in measurement. The intended use of the DASES was meant to measure the level of self-efficacy an individual will report while recovering from substance use. However, Martin et al. (1995) stated that the DASES was designed to measure self-efficacy concerning avoidance of substance use by multiple-drug users. Although the current study included participants with poly-substance use, the use of a more specific measure related to relapse may be necessary. A more appropriate measure that could be utilized in future research is the Alcohol and Drug Use Self-Efficacy Scale (ADUSE; Brown, Seraganian, Tremblay, \& Annis, 2002). The ADUSE was designed to specifically measure self-efficacy with respect to temptations to use and self-confidence in the face of high-risk situations (Brown et al., 2002). Future research should consider the use of this measure when assessing for self-efficacy in individuals abstaining from drug and alcohol use.

The final limitation related to the current study's research design is that of employing a cross-sectional design. The current study employed a one-time measurement of each of the 
variables within a population of individuals recovering from substance use. Since one of the variables was that of relapse, the use of a longitudinal design would offer more specific points of measurement across time. Limitations of a cross-sectional design include the inability to analyze behavior over time, being unable to determine cause and effect, and lack of representation of the population. Additionally, the original use of the AWARE measure was implemented in a longitudinal design. Miller and Harris (2000) measured relapse risk during follow-up intervals of time including four months, six months, eight months, 10 months, and 12 months. In future research, assessing relapse risk would be better suited in a longitudinal design at marked time lapses throughout substance use treatment.

Data analysis and findings. The first limitation in data analysis includes the removal of participants' incomplete data. A total of 10 survey responses were not included in the analyses due to incomplete data. Upon visual inspection of the dataset, these participants' data did not reveal a systematic pattern of incompletion. It is suspected that these 10 participants' data were incomplete due to test fatigue. However, the measures were counterbalanced in the current study; therefore, the cause of incompletion cannot be confirmed.

Future research should explore more complex data analyses to further investigate the associations between the factors of self-compassion, mindfulness, self-efficacy and relapse risk. One possible analysis that could be explored in future research is moderated regression.. A moderated regression would assist in determining whether self-compassion influences the strength or direction of the relationship between trait mindfulness, self-efficacy, and relapse risk. To determine the order of the relationship between these variables, the more complex statistical analysis of structural equation modeling could be utilized in future research. The current findings begin to embark on possible relationships among these variables and warrant future research 
with the goal of understanding these relationships and promoting clinical application to individuals recovering from substance use.

In addition, the SCS-SF and FFMQ-SF include several subscales as part of the measure, and investigation into how their respected components relate to the current findings could yield enlightening results that would further fill gaps in the literature. For example, the SCS-SF includes six subscales (self-kindness, self-judgment, common humanity, isolation, mindfulness, and over-identified) and the FFMQ-SF included five subscales (observe, describe, acting with awareness, nonjudging of inner experience, and nonreactivity to inner experience). The current results indicate a relationship exists between self-efficacy, trait mindfulness, self-compassion, and relapse risk, but the analyses did not specify relationships with subscale scores. Future research with larger samples should explore the specific subscales of these constructs to determine the strength and direction of any possible associations.

Threats to External Validity. Regarding the findings of the study, three limitations stand out that should be considered for the future directions of the literature. First, the lack of different groups of participants throughout data collection resulted in an additional lack of information regarding causality. Without a control group, it is difficult to conclude that low self-compassion is related to relapse risk in individuals recovering from substance use. Future research could benefit from including groups of participants recovering from substance use assigned to differently oriented therapies derived from the theories of self-efficacy, mindfulness, and selfcompassion as well as a control group in order to strengthen the validity of concluding the relationship between the respected variables. Combining this experimental design with regression models would produce directional relationships among these variables, which would eventually benefit clinical practice. 
The second limitation to be considered from the current study includes the collection of information from participants regarding their reported number of times of relapse in the past six months as well as number of times participants reported being in substance use treatment. These demographic characteristics were not considered for the primary analyses because of the specific hypotheses examining the relationships among self-efficacy, trait mindfulness, self-compassion, and relapse risk. This is a limitation in this study, due to self-reported variables presenting the potential for self-servicing bias. Further research in this area should consider objective measurements of the number of relapse occurrences and number of times in substance use treatment for this populations. Validity would be strengthened if these objective measures were utilized. Additionally, if future studies were to use these demographic variables, it would assist in further validating the relationships among self-efficacy, trait mindfulness, self-compassion, and relapse risk. Since research examining the relationship between self-compassion and relapse is in its infancy, Phelps et al. (2018) stated future research could explore if self-compassion would improve treatment outcomes for individuals in substance use treatment.

An additional component for future research to consider is that self-compassion can be taught through the treatment model of compassionate mind-training (CMT) (Gilbert \& Procter, 2006). Gilbert and Procter (2006) reported that CMT was "developed for people with high shame and self-criticism, whose problems tend to be chronic, and who find self-warmth and selfacceptance difficult and/or frightening” (p. 353). For individuals recovering from substance use, it has been previously found that obstacles in abstinence include feelings of failure, guilt, selfhatred, and self-blame (Uslaner et al., 1999) as well as negative affective states (Brown et al., 1989). Engaging in CMT suggests that the more an individual engages in self-compassion practices, the more they will learn these techniques and possibly lessen their chances of relapse 
and increase their lapses of abstinence. As stated previously, an additional treatment component that has been found useful in substance use populations is mindfulness-based relapse prevention (MBRP) (Bowen, Chawla, \& Marlatt, 2010; Witkiewitz et al., 2005). These findings indicate that MBRP can develop awareness and acceptance of thoughts, feelings, and sensations through practicing mindfulness as a way to cope with cravings and triggers for relapse (Witkiewitz et al., 2005). After eight weeks enrolled in a MBRP program, significant decreases have been found in overall days of substance use, cravings, and significant increases in acceptance and acting with awareness post-intervention (Bowen et al., 2009). With the possibilities introduced by CMT and the findings from research examining the usefulness of MBRP, future research would be warranted to explore the possibility of comparing rates of relapse for individuals enrolled in either of these programs and enrolled in these programs combined.

Though the results of the present study found that self-compassion did not account for a significant amount of additional variance in relapse risk compared to self-efficacy and trait mindfulness, a negative association between self-compassion and relapse risk was still supported. Considering this association was found in the primary analyses, the relationship between self-compassion and relapse risk remains unclear. Future research should continue to explore these variables to determine appropriate implementation of clinical treatment within substance use treatment programs.

Lastly, drug of choice was used in the current study as a demographic item. It is important to note the distinctions between individuals with different substance use disorders; specifically, within the variables measured in the primary analyses. For example, Hser, Huang, Brecht, Li, and Evans (2008) reported variation among participants with different substances of choice (i.e., heroin, cocaine, methamphetamine). The results of their study indicated that 
individuals who used heroin used 13 to 18 days per month, individuals who used cocaine used 8 to 11 days per months, and individuals who used meth used approximately 12 days per month (Hser et al., 2008). Though all participants in the current study were reported having a specific substance of choice, the various substances of choice could vary in severity, likelihood of relapse, and treatment utilization. For example, some individuals diagnosed with a cocaine use disorder may require more mindfulness-based relapse prevention programs to lessen likelihood of relapse, whereas individuals diagnosed with an opioid-use disorder may require more selfcompassion-oriented treatment to lessen likelihood of relapse. Perhaps future research can explore substance of choice, self-compassion, self-efficacy, and trait mindfulness. The exploration of these relationships can specify differences in internal variables (i.e., selfcompassion, self-efficacy, trait mindfulness) between users of different substances which may provide information on how to effectively tailor substance use treatment.

\section{Conclusion}

The main findings of this study include the reinforcement of the relationships between self-efficacy, trait mindfulness, and relapse risk, while also illustrating a relationship between self-compassion and relapse risk. The finding of a relationship between self-compassion and relapse risk warrants consideration regarding the implementation of self-compassion in addition to mindfulness practices in applied substance use treatment settings. It is essential that these variables continued to be researched and their relationship to substance use treatment examined in order to initiate the implementation of these practices conjointly throughout clinical practice. Identification of effective implementation of these practices also requires further study. As researchers further explore evidence-based practices that may be effective with the substance use population, mental health professionals should consider various aspects of trait mindfulness, self- 
compassion, self-efficacy and relapse risk as they continue to develop innovative treatment programs.

Based on the current study's findings, it would be beneficial for mental health professionals to consider ways to teach and train the elements of self-efficacy, mindfulness, and self-compassion practices to their clients/patients. In order to do this, further large-scale research should be conducted to observe the effects of including self-compassion training for substance use treatment. This research would prove to be beneficial in combination with previouslyestablished evidence-based substance use treatment programs such as those oriented towards self-efficacy and mindfulness. We, as treatment professionals, must also understand if and how self-compassion can be utilized to strengthen recovery and lessen the risk of relapse. If research finds further strength to the notion of including this element in treatment settings, we must then begin offering workshops and training seminars for those who treat individuals in substance use treatment to gain training and experience in these areas themselves. Overall, the current findings of the present study imply the value of including self-compassion practices into substance use treatment to lower relapse risk for those in substance use recovery. 
Table 1

Descriptive Statistics and Correlations for Study Variables

\begin{tabular}{|c|c|c|c|c|c|c|c|}
\hline Variable & $n$ & $M$ & $S D$ & 1 & 2 & 3 & 4 \\
\hline $\begin{array}{l}\text { Relapse } \\
\text { risk } \\
\text { (AWARE) }\end{array}$ & 79 & 96.64 & 25.84 & - & & & \\
\hline $\begin{array}{l}\text { Self- } \\
\text { compassion } \\
(\mathrm{SCS}-\mathrm{SF})\end{array}$ & 86 & 33.92 & 8.24 & $-.47 * *$ & - & & \\
\hline $\begin{array}{l}\text { Self- } \\
\text { efficacy } \\
\text { (DASES) }\end{array}$ & 86 & 88.60 & 19.44 & $-.64 * *$ & $.44 * *$ & - & \\
\hline $\begin{array}{l}\text { Trait } \\
\text { mindfulness } \\
\text { (FFMQ-SF) }\end{array}$ & 85 & 76.38 & 12.59 & $-.65 * *$ & $.58 * *$ & $.60 * *$ & - \\
\hline
\end{tabular}

$* p<.05 . * * p<.01$ 
Table 2

Hierarchical Regression Results for Relapse Risk

\begin{tabular}{|c|c|c|c|c|c|c|c|}
\hline \multirow[t]{2}{*}{ Variable } & \multirow[t]{2}{*}{$B$} & \multicolumn{2}{|c|}{$95 \% \mathrm{CI}$ for $B$} & \multirow[t]{2}{*}{$S E B$} & \multirow[t]{2}{*}{$\beta$} & \multirow[t]{2}{*}{$R^{2}$} & \multirow[t]{2}{*}{$\Delta R^{2}$} \\
\hline & & $L L$ & $U L$ & & & & \\
\hline Step 1 & & & & & & .42 & $.42 * * *$ \\
\hline Constant & $174.50 * * *$ & 152.87 & 196.13 & 10.86 & & & \\
\hline Self-efficacy & $-.87 * * *$ & -1.10 & -.63 & 0.12 & $-.65 * * *$ & & \\
\hline Step 2 & & & & & & .54 & $.13 * * *$ \\
\hline Constant & $212.57 * * *$ & 187.03 & 238.11 & 12.82 & & & \\
\hline Self-efficacy & $-.52 * * *$ & -.78 & -.26 & 0.13 & $-.39 * * *$ & & \\
\hline Trait mindfulness & $-.90 * * *$ & -1.29 & -.50 & 0.20 & $-.44 * * *$ & & \\
\hline Step 3 & & & & & & .54 & .00 \\
\hline Constant & $212.75 * * *$ & 187.04 & 238.45 & 12.90 & & & \\
\hline Self-efficacy & $-.51 * * *$ & -.78 & -.24 & 0.13 & $-.38 * * *$ & & \\
\hline Trait mindfulness & $-.86 * * *$ & -1.30 & -.41 & 0.23 & $-.42 * * *$ & & \\
\hline Self-compassion & -.13 & -.76 & .49 & 0.31 & -.04 & & \\
\hline
\end{tabular}

Note. $\mathrm{CI}=$ confidence interval; $L L=$ lower limit; $U L=$ upper limit.

$* p<.05 . * * p<.01 . * * * p<.001$. 
Table 3

Demographic Characteristics of Participants

\begin{tabular}{lcc}
\hline \multicolumn{1}{c}{ Characteristic } & \multicolumn{2}{c}{ Full sample } \\
\cline { 2 - 3 } & $n$ & $\%$ \\
\hline Gender & 44 & 50.6 \\
Male & 42 & 48.3 \\
Female & 1 & 1.1 \\
Transgender M2F & & \\
Ethnic/Racial Identity & 6 & 7 \\
African American or Black & 1 & 1.2 \\
Hispanic or Latino/a & 77 & 89.5 \\
Caucasian American or White & 2 & 2.3 \\
Biracial or Multicultural American & & \\
Primary Drug of Choice & 7 & 8 \\
Alcohol & 6 & 6.9 \\
Crack & 29 & 33.3 \\
Heroin & 18 & 20.7 \\
Methamphetamine & 4 & 4.6 \\
Cocaine & 3 & 3.4 \\
Amphetamines "Uppers" & 4 & 4.6 \\
Benzodiazepines "Downers" & 4 & 4.6 \\
Marijuana & 12 & 13.8 \\
Other & & \\
Frequency of Group Participation & 1 & 1.3 \\
None & 27 & 34.6 \\
Daily & 30 & 38.5 \\
Weekly & 15 & 19.2 \\
Bi-Weekly & 5 & 6.4 \\
Multiple Days Per Week & & \\
\hline & & \\
\hline
\end{tabular}

Note. $N=87$. Participants were on average 35.2 years old $(S D=8.6)$. 
Table 4

Means and Standard Deviations for Demographic Characteristics

\begin{tabular}{|c|c|c|c|c|c|}
\hline Characteristic & $M$ & $M d n$ & Mode & $S D$ & Range \\
\hline Age & 35.2 & 34 & 29 & 8.6 & $19-62$ \\
\hline Times in Treatment & 4.6 & 3 & 1 & 3.9 & $1-18$ \\
\hline $\begin{array}{l}\text { Number of Relapses in } \\
\text { Past } 6 \text { Months }\end{array}$ & 8.1 & 2 & 0 & 23.2 & $0-180$ \\
\hline $\begin{array}{l}\text { Current Treatment } \\
\text { Duration (Days) }\end{array}$ & 398.6 & 60 & 60 & 771 & $2-3650$ \\
\hline Household Income & 22633.5 & 12000 & 0 & 28337.9 & $0-130000$ \\
\hline
\end{tabular}


Table 5

Summary of Multiple Regression Analyses for Predictors of Relapse Risk

\begin{tabular}{|c|c|c|c|c|c|c|c|c|c|c|c|c|}
\hline \multirow[t]{2}{*}{ Variables } & \multicolumn{3}{|c|}{$\begin{array}{c}\text { Model 1 } \\
\text { Control Variables } \\
R^{2}=.14, \Delta R^{2}=.14 \\
(S E=25.06)\end{array}$} & \multicolumn{3}{|c|}{$\begin{array}{c}\text { Control Variables }+ \text { Self- } \\
\text { Compassion } \\
R^{2}=.36, \Delta R^{2}=.23 \\
(S E=21.66)\end{array}$} & \multicolumn{3}{|c|}{$\begin{array}{c}\text { Model } 3 \\
\begin{array}{c}\text { Control Variables }+ \text { Self- } \\
\text { Compassion }+ \text { Self- } \\
\text { Efficacy } \\
R^{2}=.56, \Delta R^{2}=.18 \\
(S E=18.52)\end{array}\end{array}$} & \multicolumn{3}{|c|}{$\begin{array}{c}\text { Model } 4 \\
\text { Control Variables }+ \text { Self- } \\
\text { Compassion }+ \text { Self- } \\
\text { Efficacy + Trait } \\
\text { Mindfulness } \\
\\
R^{2}=.61, \Delta R^{2}=.06 \\
(S E=17.36)\end{array}$} \\
\hline & $B$ & $S E B$ & $\beta$ & $B$ & $S E B$ & $\beta$ & $B$ & $S E B$ & $B$ & $B$ & $S E B$ & $\beta$ \\
\hline $\begin{array}{l}\text { Self- } \\
\text { Compassion }\end{array}$ & -- & -- & -- & -1.45 & .31 & $* *_{-} .49$ & -.66 & .31 & $*_{-.22}$ & -.18 & .33 & -.06 \\
\hline Self-Efficacy & -- & -- & -- & -- & -- & -- & -.68 & .14 & $* *_{-} .52$ & -.48 & .15 & $*-.37$ \\
\hline $\begin{array}{l}\text { Trait } \\
\text { Mindfulness }\end{array}$ & -- & -- & -- & -- & -- & -- & -- & -- & -- & -.76 & .25 & $*_{-.38}$ \\
\hline Race & -13.42 & 11.03 & -.15 & -9.79 & 9.57 & -.11 & -.60 & 8.40 & -.01 & 1.34 & 7.90 & .02 \\
\hline Gender & -5.02 & 6.28 & -.10 & -6.45 & 5.44 & -.12 & -7.64 & 4.66 & -.15 & -3.78 & 4.55 & -.07 \\
\hline Age & -1.07 & .37 & -.35 & -.79 & .33 & $*_{-.26}$ & -.55 & .29 & -.18 & -.57 & .27 & -*.19 \\
\hline $\begin{array}{l}\text { Group } \\
\text { Participation }\end{array}$ & 1.82 & 2.75 & .08 & 2.12 & 2.38 & .09 & .98 & 2.05 & 1.00 & 1.92 & .04 & .52 \\
\hline
\end{tabular}

Note. $n=65 ; * p<.05 ; * * \mathrm{p}<.01$ 
Table 6

Trait Mindfulness as a Mediator between Predictor of Self-Compassion and Outcome of Relapse Risk

\begin{tabular}{|c|c|c|c|c|c|c|c|c|c|c|c|c|}
\hline \multirow[t]{2}{*}{ Variables } & \multicolumn{3}{|c|}{$\begin{array}{c}\begin{array}{c}\text { Model } 1 \\
\text { Self-Compassion on } \\
\text { Relapse Risk }\end{array} \\
R^{2}=.222(S E=22.93)\end{array}$} & \multicolumn{3}{|c|}{$\begin{array}{l}\frac{\text { Model 2 }}{\text { Self-Compassion on }} \\
\text { Trait Mindfulness } \\
R^{2}=.337(S E=10.32)\end{array}$} & \multicolumn{3}{|c|}{$\begin{array}{c}\begin{array}{c}\text { Model } 3 \\
\text { Trait Mindfulness on } \\
\text { Relapse Risk }\end{array} \\
R^{2}=.418(S E=19.93)\end{array}$} & \multicolumn{3}{|c|}{$\begin{array}{l}\text { Model } 4 \\
\text { Self-Compassion and } \\
\text { Trait Mindfulness on } \\
\text { Relapse Risk } \\
R^{2}=.431(S E=19.84)\end{array}$} \\
\hline & $B$ & $S E B$ & $B$ & $B$ & $S E B$ & $\beta$ & $B$ & $S E B$ & $B$ & $B$ & $S E B$ & $\beta$ \\
\hline $\begin{array}{l}\text { Self- } \\
\text { Compassion }\end{array}$ & -.1 .46 & .32 & $* *-.47$ & .88 & .14 & $* * .58$ & -- & -- & -- & -.43 & .34 & -.14 \\
\hline $\begin{array}{l}\text { Trait } \\
\text { Mindfulness }\end{array}$ & -- & -- & -- & -- & -- & -- & -1.30 & .18 & $* *-.65$ & -1.13 & .22 & $* *-.56$ \\
\hline
\end{tabular}


Figure 1

Mediation Model with Self-Compassion, Trait Mindfulness, and Relapse Risk

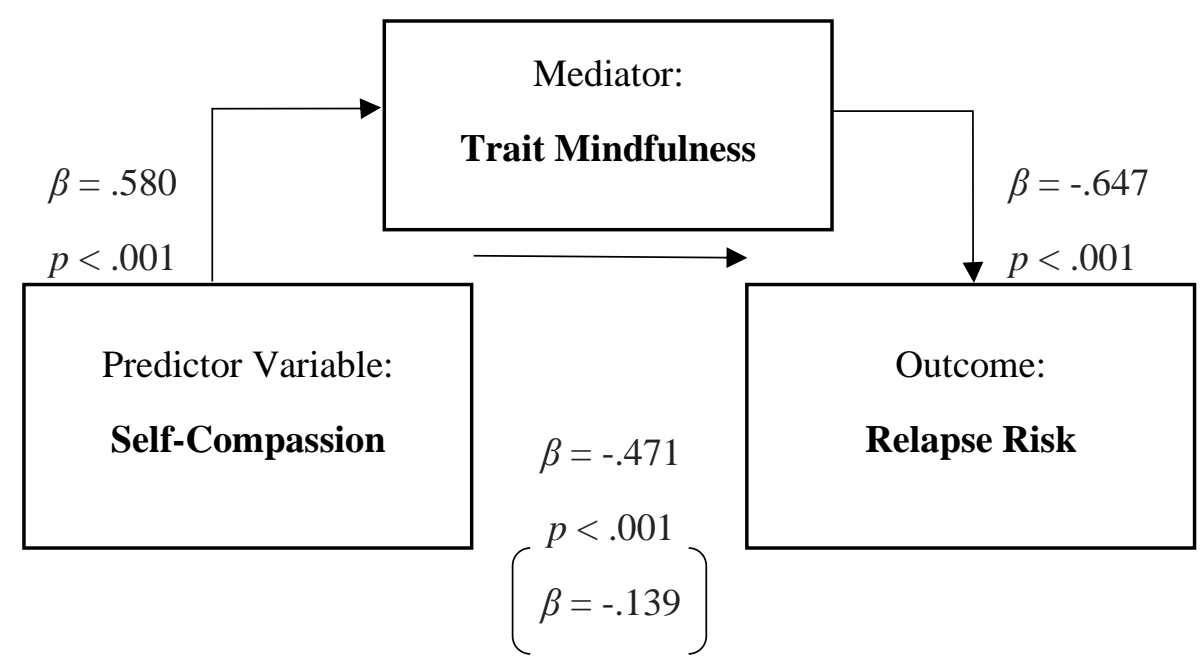

Figure 1. Model testing mediation of the relationship between self-compassion and relapse risk by trait mindfulness. Values in parentheses represent the standardized relation of selfcompassion to relapse risk after controlling for trait mindfulness. 


\section{REFERENCES}

Appel, J., \& Kim-Appel, D. (2009). Mindfulness: Implications for substance abuse and addiction. International Journal of Mental Health and Addiction, 7(4), 506-512. doi:10.1007/s11469-009-9199-z

Bandura, A. (1977). Self-efficacy: Toward a unifying theory of behavioral change. Psychological Review, 84(2), 191-215. doi:10.1037/0033-295x.84.2.191

Bandura, A. (1982). Self-efficacy mechanism in human agency. American Psychologist, 37(2), 122-147. doi:10.1037/0003-066x.37.2.122

Bandura, A. (1993). Perceived self-Efficacy in cognitive development and functioning. Educational Psychologist, 28(2), 117-148. doi:10.1207/s15326985ep2802_3

Bandura, A. (1999). Social cognitive theory: An agentic perspective. Asian Journal of Social Psychology, 2(1), 21-41. doi:10.1111/1467-839x.00024

Baron, R. M., \& Kenny, D. A. (1986). The moderator-mediator variable distinction in social psychological research: Conceptual, strategic, and statistical considerations. Journal of Personality and Social Psychology, 51(6), 1173-1182. doi: 10.1037/0022-3514.51.6.1173

Bohlmeijer, E., ten Klooster, P. M., Fledderus, M., Veehof, M., \& Baer, R. (2011). Five Facet Mindfulness Questionnaire--Short Form [Database record]. Retrieved from PsycTESTS. doi: http://dx.doi.org/10.1037/t35565-000

Bohlmeijer, E., ten Klooster, P. M., Fledderus, M., Veehof, M., \& Baer, R. (2011). Psychometric properties of the Five Facet Mindfulness Questionnaire in depressed adults and development of a short form. Assessment, 18(3), 308-320. doi:10.1177/1073191111408231 
Bowen, S., Chawla, N., Collins, S. E., Witkiewitz, K., Hsu, S., Grow, J., ... Marlatt, A. (2009). Mindfulness-based relapse prevention for substance use disorders: A pilot efficacy trial. Substance Abuse, 30(4), 295-305. doi:10.1080/08897070903250084

Bowen, S., Chawla, N., \& Marlatt, G. A. (2010) Mindfulness-based relapse prevention for addictive behaviors: A clinician's guide. New York, NY: Guilford Press.

Bowen, S., \& Enkema, M. C. (2014). Relationship between dispositional mindfulness and substance use: Findings from a clinical sample. Addictive Behaviors, 39(3), 532-537. doi:10.1016/j.addbeh.2013.10.026

Bowen, S., Witkiewitz, K., Clifasefi, S. L., Grow, J., Chawla, N., Hsu, S. H., ... Larimer, M. E. (2014). Relative efficacy of mindfulness-based relapse prevention, standard relapse prevention, and treatment as usual for substance use disorders. JAMA Psychiatry, 71(5), 547. doi:10.1001/jamapsychiatry.2013.4546

Bowen, S., Witkiewitz, K., Dillworth, T. M., Chawla, N., Simpson, T. L., Ostafin, B. D., ... \& Marlatt, G. A. (2006). Mindfulness meditation and substance use in an incarcerated population. Psychology of Addictive Behaviors, 20(3), 343. doi:10.1037/0893$164 x .20 .3 .343$

Brandon, T. H., Vidrine, J. I., \& Litvin, E. B. (2007). Relapse and relapse prevention. Annual Review of Clinical Psychology, 3(1), 257-284. doi:10.1146/annurev.clinpsy.3.022806.091455

Brewer, J. A., Sinha, R., Chen, J. A., Michalsen, R. N., Babuscio, T. A., Nich, C., ... Rounsaville, B. J. (2009). Mindfulness training and stress reactivity in substance abuse: Results from a randomized, controlled stage I pilot study. Substance Abuse, 30(4), 306317. doi:10.1080/08897070903250241 
Brooks, M., Kay-Lambkin, F., Bowman, J., \& Childs, S. (2012). Self-compassion amongst clients with problematic alcohol use. Mindfulness, 3(4), 308-317. doi:10.1007/s12671012-0106-5

Brown, K. W., \& Ryan, R. M. (2003). The benefits of being present: Mindfulness and its role in psychological well-being. Journal of Personality and Social Psychology, 84(4), 822-848. doi:10.1037/0022-3514.84.4.822

Brown, S. A., Vik, P. W., \& Creamer, V. A. (1989). Characteristics of relapse following adolescent substance abuse treatment. Addictive Behaviors, 14(3), 291-300. doi:10.1016/0306-4603(89)90060-9

Burling, T. A., Reilly, P. M., Moltzen, J. O., \& Ziff, D. C. (1989). Self-efficacy and relapse among inpatient drug and alcohol abusers: A predictor of outcome. Journal of Studies on Alcohol, 50(4), 354-360. doi:10.15288/jsa.1989.50.354

Caselli, G., Ferretti, C., Leoni, M., Rebecchi, D., Rovetto, F., \& Spada, M. M. (2010). Rumination as a predictor of drinking behaviour in alcohol abusers: a prospective study. Addiction, 105(6), 1041-1048. doi:10.1111/j.1360-0443.2010.02912.x

Diclemente, C. C. (1986). Self-efficacy and the addictive behaviors. Journal of Social and Clinical Psychology, 4(3), 302-315. doi:10.1521/jscp.1986.4.3.302

Donovan, D. M. (1996). Assessment issues and domains in the prediction of relapse. Addiction, 91(12), 29-36. doi:10.1080/09652149638782

Drake, R. E., Wallach, M. A., \& McGovern, M. P. (2005). Special section on relapse prevention: Future directions in preventing relapse to substance abuse among clients with severe mental illnesses. Psychiatric Services, 56(10), 1297-1302. doi:10.1176/appi.ps.56.10.1297 
El, S., El, G., \& Bashir, T. Z. (2004). High-risk relapse situations and self-efficacy: Comparison between alcoholics and heroin addicts. Addictive Behaviors, 29(4), 753-758. doi:10.1016/j.addbeh.2004.02.003

Fernandez, A. C., Wood, M. D., Stein, L. A. R., \& Rossi, J. S. (2010). Measuring mindfulness and examining its relationship with alcohol use and negative consequences. Psychology of Addictive Behaviors, 24(4), 608-616. doi:10.1037/a0021742

Garland, E. L., Boettiger, C. A., Gaylord, S., Chanon, V. W., \& Howard, M. O. (2011). Mindfulness is inversely associated with alcohol attentional bias among recovering alcohol-dependent adults. Cognitive Therapy and Research, 36(5), 441-450. doi:10.1007/s10608-011-9378-7

Garland, E. L., Roberts-Lewis, A., Kelley, K., Tronnier, C., \& Hanley, A. (2014). Cognitive and affective mechanisms linking trait mindfulness to craving among individuals in addiction recovery. Substance Use \& Misuse, 49(5), 525-535. doi:10.3109/10826084.2014.850309

Garner, A. R., Gilbert, S. E., Shorey, R. C., Gordon, K. C., Moore, T. M., \& Stuart, G. L. (2020). A longitudinal investigation on the relation between self-compassion and alcohol use in a treatment sample: A brief report. Substance Abuse: Research and Treatment, 14, 1-5. doi: $10.1177 / 1178221820909356$

Hunt, W. A., Barnett, L. W., \& Branch, L. G. (1971). Relapse rates in addiction programs. Journal of Clinical Psychology, 27(4), 455-456. doi: 10.1002/10974679(197110)27:4<455::AID-JCLP2270270412>3.0.CO;2-R

Ilgen, M., McKellar, J., \& Moos, R. (2007). Personal and treatment-related predictors of abstinence self-efficacy. Journal of Studies on Alcohol and Drugs, 68(1), 126-132. doi:10.15288/jsad.2007.68.126 
Ilgen, M., McKellar, J., \& Tiet, Q. (2005). Abstinence self-efficacy and abstinence 1 year after substance use disorder treatment. Journal of Consulting and Clinical Psychology, 73(6), 1175-1180. doi:10.1037/0022-006x.73.6.1175

Ilgen, M., Tiet, Q., Finney, J., \& Moos, R. H. (2006). Self-efficacy, therapeutic alliance, and alcohol-use disorder treatment outcomes. Journal of Studies on Alcohol, 67(3), 465-472. doi:10.15288/jsa.2006.67.465

Iskender, M. (2009). The relationship between self-compassion, self-efficacy, and control belief about learning in Turkish University students. Social Behavior and Personality: An International Journal, 37(5), 711-720. doi:10.2224/sbp.2009.37.5.711

Irvin, J. E., Bowers, C. A., Dunn, M. E., \& Wang, M. C. (1999). Efficacy of relapse prevention: A meta-analytic review. Journal of Consulting and Clinical Psychology, 67(4), 563-570. doi:10.1037/0022-006x.67.4.563

Kabat-Zinn, J. (1990). Full catastrophe living: Using the wisdom of your body and mind to face stress, pain and illness. New York, NY: Delacorte.

Karyadi, K. A., \& Cyders, M. A. (2015). Elucidating the association between trait mindfulness and alcohol use behaviors among college students. Mindfulness, 6(6), 1242-1249. doi:10.1007/s12671-015-0386-7

Karyadi, K. A., VanderVeen, J. D., \& Cyders, M. A. (2014). A meta-analysis of the relationship between trait mindfulness and substance use behaviors. Drug and Alcohol Dependence, 143, 1-10. doi:10.1016/j.drugalcdep.2014.07.014

Kelly, J. F., \& Greene, M. C. (2014). Where there's a will there's a way: A longitudinal investigation of the interplay between recovery motivation and self-efficacy in predicting 
treatment outcome. Psychology of Addictive Behaviors, 28(3), 928-934.

doi:10.1037/a0034727

Kelly, J. F., Hoeppner, B. B., Urbanoski, K. A., \& Slaymaker, V. (2011). Predicting relapse among young adults: Psychometric validation of the advanced warning of relapse (AWARE) scale. Addictive Behaviors, 36(10), 987-993.

doi:10.1016/j.addbeh.2011.05.013

Kiken, L. G., Garland, E. L., Bluth, K., Palsson, O. S., \& Gaylord, S. A. (2015). From a state to a trait: Trajectories of state mindfulness in meditation during intervention predict changes in trait mindfulness. Personality and Individual Differences, 81, 41-46. doi:10.1016/j.paid.2014.12.044

Leary, M. R., Tate, E. B., Adams, C. E., Batts Allen, A., \& Hancock, J. (2007). Self-compassion and reactions to unpleasant self-relevant events: The implications of treating oneself kindly. Journal of Personality and Social Psychology, 92(5), 887-904. doi:10.1037/00223514.92.5.887

Leigh, J., Bowen, S., \& Marlatt, G. A. (2005). Spirituality, mindfulness and substance abuse. Addictive Behaviors, 30(7), 1335-1341. doi:10.1016/j.addbeh.2005.01.010

Leigh, J., \& Neighbors, C. (2009). Enhancement motives mediate the positive association between mind/body awareness and college student drinking. Journal of Social and Clinical Psychology, 28(5), 650-669. doi:10.1521/jscp.2009.28.5.650

Marlatt, G. (1985). Relapse prevention: Theoretical rationale and overview of the model. In Relapse Prevention, ed. Marlatt, G. A., \& Gordon, J. R. pp. 3-70. New York, NY: Guilford. 
Marlatt, G. A., \& George, W. H. (1984). Relapse prevention: Introduction and overview of the model. Addiction, 79(4), 261-273. doi:10.1111/j.1360-0443.1984.tb03867.x

Marlatt, G. A. \& Gordon, J. R. (Eds.) (1985). Relapse prevention: Maintenance strategies in the treatment of addictive behaviors. New York, NY: Guilford Press.

Martin, G. W., Wilkinson, D. A., \& Poulos, C. X. (1995). The drug avoidance self-efficacy scale. Journal of Substance Abuse, 7(2), 151-163. doi:10.1016/0899-3289(95)90001-2

Miller, W. R. (1996). What is a relapse? Fifty ways to leave the wagon. Addiction, 91(12), 1528. doi:10.1080/09652149638773

Miller W. R., \& Harris R. J. (2000) A simple scale of Gorski's warning signs for relapse. Journal of Studies on Alcohol, 61(5), 759-765. doi: 10.15288/jsa.2000.61.759

Miller, W. R., Westerberg, V. S., Harris, R. J., \& Tonigan, J. S. (1996). What predicts relapse? Prospective testing of antecedent models. Addiction, 91(12), 155-172. doi:10.1080/09652149638890

Miron, L. R., Orcutt, H. K., Hannan, S. M., \& Thompson, K. L. (2014). Childhood abuse and problematic alcohol use in college females: The role of self-compassion. Self and Identity, 13(3), 364-379. doi:10.1080/15298868.2013.836131

Moos, R. H., \& Finney, J. W. (1983). The expanding scope of alcoholism treatment evaluation. American Psychologist, 38(10), 1036-1044. doi:10.1037/0003-066x.38.10.1036

Moos, R. H., \& Moos, B. S. (2006). Rates and predictors of relapse after natural and treated remission from alcohol use disorders. Addiction, 101(2), 212-222. doi:10.1111/j.13600443.2006.01310.x

Neff, K. (2003). The development and validation of a scale to measure self-compassion. Self and Identity, 2(3), 223-250. doi:10.1080/15298860309027 
Neff, K. (2003). Self-compassion: An alternative conceptualization of a healthy attitude toward oneself. Self and Identity, 2(2), 85-101. doi:10.1080/15298860309032

Neff, K. (2004). Self-compassion and psychological well-being. Constructivism in the Human Sciences, 9(2), 27-37. doi:10.1037/e633942013-240

NIDA. (2017, April 24). Trends \& Statistics. Retrieved from https://www.drugabuse.gov/relatedtopics/trends-statistics

NIDA. (2015, June 25). Nationwide Trends. Retrieved from https://www.drugabuse.gov/publications/drugfacts/nationwide-trends

Phelps, C. L., Paniagua, S. M., Willcockson, I. U., \& Potter, J. S. (2018). The relationship between self-compassion and the risk for substance use disorder. Drug and Alcohol Dependence, 183, 78-81. doi:10.1016/j.drugalcdep.2017.10.026

Polivy, J., \& Herman, C. P. (2002). If at first you don't succeed: False hopes of selfchange. American Psychologist, 57(9), 677-689. doi: 10.1037//0003-066X.57.9.677

Shorey, R. C., Anderson, S., \& Stuart, G. L. (2014). Trait mindfulness and early maladaptive schemas in women seeking residential substance use treatment: A preliminary investigation. Addiction Research \& Theory, 23(4), 280-286. doi:10.3109/16066359.2014.981810

Shorey, R. C., Brasfield, H., Anderson, S., \& Stuart, G. L. (2014). The relation between trait mindfulness and early maladaptive schemas in men seeking substance use treatment. Mindfulness, 6(2), 348-355. doi:10.1007/s12671-013-0268-9

Shorey, R. C., Brasfield, H., Anderson, S., \& Stuart, G. L. (2013). Mindfulness deficits in a sample of substance abuse treatment seeking adults: a descriptive investigation. Journal of Substance Use, 19(1-2), 194-198. doi:10.3109/14659891.2013.770570 
Taber, K. S. (2017). The use of Cronbach's alpha when developing and reporting research instruments in science education. Research in Science Education, 48(6), 1273-1296. doi:10.1007/s11165-016-9602-2Raes, F., Pommier, E., Neff, K. D., \& Van Gucht, D. (2010). Construction and factorial validation of a short form of the Self-Compassion Scale. Clinical Psychology \& Psychotherapy, 18(3), 250-255. doi:10.1002/cpp.702

Ramo, D. E., Anderson, K. G., Tate, S. R., \& Brown, S. A. (2005). Characteristics of relapse to substance use in comorbid adolescents. Addictive Behaviors, 30(9), 1811-1823. doi:10.1016/j.addbeh.2005.07.021

Rendon, K. P. (2007). Understanding alcohol use in college students: A study of mindfulness, self-compassion, and psychological symptoms. Unpublished doctoral dissertation, University of Texas at Austin, TX, USA.

Results From the 2013 National Survey on Drug Use and Health: National Findings. (n.d.). PsycEXTRA Dataset. doi:10.1037/e592592009-001

Robinson, J. M., Ladd, B. O., \& Anderson, K. G. (2014). When you see it, let it be: Urgency, mindfulness, and adolescent substance use. Addictive Behaviors, 39(6), 1038-1041. doi:10.1016/j.addbeh.2014.02.011

Roos, C. R., Bowen, S., \& Witkiewitz, K. (2017). Baseline patterns of substance use disorder severity and depression and anxiety symptoms moderate the efficacy of mindfulnessbased relapse prevention. Journal of Consulting and Clinical Psychology, 85(11), 10411051. doi:10.1037/ccp0000249

Rudd, R. A., Seth, P., David, F., \& Scholl, L. (2016). Increases in drug and opioid-involved overdose deaths — United States, 2010-2015. MMWR. Morbidity and Mortality Weekly Report, 65(5051), 1445-1452. doi:10.15585/mmwr.mm655051e1 
Segal, Z. V., Williams, J. M. G., \& Teasdale, J. D. (2002). Mindfulness-based cognitive therapy for depression: A new approach to preventing relapse. New York, NY: The Guilford Press.

Shorey, R. C., Anderson, S., \& Stuart, G. L. (2014). Trait mindfulness and early maladaptive schemas in women seeking residential substance use treatment: A preliminary investigation. Addiction Research \& Theory, 23(4), 280-286.

doi:10.3109/16066359.2014.981810

Shorey, R. C., Brasfield, H., Anderson, S., \& Stuart, G. L. (2014). The relation between trait mindfulness and early maladaptive schemas in men seeking substance use treatment. Mindfulness, 6(2), 348-355. doi:10.1007/s12671-013-0268-9

Tanaka, M., Wekerle, C., Schmuck, M. L., Paglia-Boak, A., \& MAP Research Team. (2011). The linkages among childhood maltreatment, adolescent mental health, and selfcompassion in child welfare adolescents. Child Abuse \& Neglect, 35(10), 887-898.

Trucco, E. M., Connery, H. S., Griffin, M. L., \& Greenfield, S. F. (2007). The relationship of self-esteem and self-efficacy to treatment outcomes of alcohol-dependent men and women. American Journal on Addictions, 16(2), 85-92. doi:10.1080/10550490601184183

Uslaner, J., Kalechstein, A., Richter, T., Ling, W., \& Newton, T. (1999). Association of depressive symptoms during abstinence with the subjective high produced by cocaine. American Journal of Psychiatry, 156(9), 1444-1446.

Vettese, L. C., Dyer, C. E., Li, W. L., \& Wekerle, C. (2011). Does self-compassion mitigate the association between childhood maltreatment and later emotion regulation difficulties? A 
preliminary investigation. International Journal of Mental Health and Addiction, 9(5), 480. doi:10.1007/s11469-011-9340-7

Walton, M. A., Blow, F. C., Bingham, C. R., \& Chermack, S. T. (2003). Individual and social/environmental predictors of alcohol and drug use 2 years following substance abuse treatment. Addictive Behaviors, 28(4), 627-642. doi:10.1016/s03064603(01)00284-2

Witkiewitz, K., Bowen, S., Douglas, H., \& Hsu, S. H. (2013). Mindfulness-based relapse prevention for substance craving. Addictive Behaviors, 38(2), 1563-1571. doi:10.1016/j.addbeh.2012.04.001

Witkiewitz, K., \& Marlatt, G. A. (2004). Relapse prevention for alcohol and drug problems: That was zen, this is tao. American Psychologist, 59(4), 224-235. doi:10.1037/0003$066 x .59 .4 .224$

Witkiewitz, K., Marlatt, G. A., \& Walker, D. (2005). Mindfulness-based relapse prevention for alcohol and substance use disorders. Journal of Cognitive Psychotherapy, 19(3), 211228. doi:10.1891/088983905780907522

Yarnell, L. M., \& Neff, K. D. (2013). Self-compassion, interpersonal conflict resolutions, and well-being. Self and Identity, 12(2), 146-159. doi:10.1080/15298868.2011.649545

Zemestani, M., \& Ottaviani, C. (2016). Effectiveness of mindfulness-based relapse prevention for co-occurring substance use and depression disorders. Mindfulness, 7(6), 1347-1355. doi:10.1007/s12671-016-0576-y

Zgierska, A., Rabago, D., Chawla, N., Kushner, K., Koehler, R., \& Marlatt, A. (2009). Mindfulness meditation for substance use disorders: A systematic review. Substance Abuse, 30(4), 266-294. doi:10.1080/08897070903250019 
ROLES IN RELAPSE RISK 


\section{APPENDICES}

\section{Appendix A: Drug Avoidance Self-Efficacy Scale}

The following 16 situations may trigger someone's intention to use substances. Please select a response for each question, indicating what you would be likely to do in each situation. Use the rating scale below.

This questionnaire is used for project evaluation only. All information will be kept confidential. Substance use refers to the use of prohibited or legal psychotropic substances e.g. ketamine, marijuana, "ice", ecstasy, alcohol, cough medicine, thinner etc. without doctor's prescription.

\begin{tabular}{|c|c|c|c|c|c|c|}
\hline 7 & 6 & 5 & 4 & 3 & 2 & 1 \\
\hline $\begin{array}{c}\text { Certainly } \\
\text { yes }\end{array}$ & $\begin{array}{c}\text { Very likely } \\
\text { yes }\end{array}$ & $\begin{array}{c}\text { Probably } \\
\text { yes }\end{array}$ & $\begin{array}{c}\text { Really can't } \\
\text { say }\end{array}$ & $\begin{array}{c}\text { Probably } \\
\text { no }\end{array}$ & $\begin{array}{c}\text { Very likely } \\
\text { no }\end{array}$ & $\begin{array}{c}\text { Certainly } \\
\text { no }\end{array}$ \\
\hline
\end{tabular}

where you will meet new people. You feel

that drug/alcohol use will relax you and make you more confident. Could you avoid substance use?

2. Imagine that you have just blown a good $\begin{array}{lllllll}7 & 6 & 5 & 4 & 3 & 2 & 1\end{array}$ job, you are home alone and depressed. Would you give in to the urge to use substances which are in the house?

3. Imagine that you are home with a loved on one, and feeling angry after a fight.

You want to make up, but at the same time you want to get stoned/loaded.

Could you resist the urge to use substances?

4. Imagine that you are feeling good and have $\begin{array}{lllllll}7 & 6 & 5 & 4 & 3 & 2 & 1\end{array}$ no responsibilities for a couple of days. The only thing you see against getting a bit stoned/loaded is that you have promised yourself you would go straight for 2 months, and you still have 3 weeks to go. Would you use?

5. Imagine it is late, you cannot sleep and $\begin{array}{rlllllll}7 & 6 & 5 & 4 & 3 & 2 & 1\end{array}$ drugs/alcohol are available in the house. You have decided not to use. Could you resist the urge to use drugs/alcohol to help you get to sleep? 
6. Imagine that a new job is starting $\begin{array}{lllllll}7 & 6 & 5 & 4 & 3 & 2 & 1\end{array}$ tomorrow, you are going out with friends and expecting a good time. Could you resist the urge to celebrate with substances?

7. Imagine that you are home with your loved $\begin{array}{lllllll}7 & 6 & 5 & 4 & 3 & 2 & 1\end{array}$ one, and very angry after a fight.

You are tempted to get back at your partner by getting stoned/loaded. Would you give in to the temptation?

\begin{tabular}{|c|c|c|c|c|c|c|}
\hline 7 & 6 & 5 & 4 & 3 & 2 & 1 \\
\hline $\begin{array}{c}\text { Certainly } \\
\text { yes }\end{array}$ & Very likely yes & Probably yes & Really can't say & Probably no & Very likely no & Certainly no \\
\hline
\end{tabular}

8. Imagine that a very important relationship has just ended, and you are very depressed Would you give in to the urge to use substances?

9. Imagine that you have run into 2 friends $\begin{array}{llllllll}7 & 6 & 5 & 4 & 3 & 2 & 1\end{array}$ who are celebrating a win at horse racing with substances. Could you resist their urging to join them in substance use?

10. Imagine that you are at a party and feeling $\begin{array}{lllllll}7 & 6 & 5 & 4 & 3 & 2 & 1\end{array}$ uptight. Most people seem to be having a good time. You are tempted to use drugs or alcohol to loosen up. Would you?

11. Imagine that you promised yourself to stay straight for 2 months but you have just blown your 5 week record with one hit or drink. Would this situation lead you to take a second one?

12. Imagine that you had managed to stay $\begin{array}{lllllll}7 & 6 & 5 & 4 & 3 & 2 & 1\end{array}$ straight for a near record time, but last night you blew it. Because of last night you are feeling weak. Would you use tonight? 13. Imagine that you are home alone and $\begin{array}{lllllll}7 & 6 & 5 & 4 & 3 & 2 & 1\end{array}$ depressed. Could you resist the urge to go out and seek substances? 
14. Imagine that a good friend has accused you of being insensitive. Now you are feeling hurt and tempted to use substances. Could you resist?

15. Imagine that a good friend is feeling miserable. He wants you to join him in heavy discussion and substance use to pick his spirits up. Could you resist the urge to use substances?

16. Imagine that you are home alone; it is a dull weekend with nothing in particular to look forward to. You are bored. Would you give in to the urge to get stoned/loaded? $\begin{array}{lllllll}7 & 6 & 5 & 4 & 3 & 2 & 1\end{array}$

$\begin{array}{lllllll}7 & 6 & 5 & 4 & 3 & 2 & 1\end{array}$

$\begin{array}{lllllll}7 & 6 & 5 & 4 & 3 & 2 & 1\end{array}$ 


\section{Appendix B: Five Facet Mindfulness Questionnaire-Short Form}

Below is a collection of statements about your everyday experience. Using the $1-5$ scale below, please indicate, in the box to the right of each statement, how frequently or infrequently you have had each experience in the last month (or other agreed time period). Please answer according to what really reflects your experience rather than what you think your experience should be.

$\begin{array}{ccccc}\begin{array}{c}\text { never or } \\ \text { very rarely true }\end{array} & \begin{array}{c}\text { not often } \\ \text { true }\end{array} & \begin{array}{c}\text { sometimes true } \\ \text { sometimes not true }\end{array} & \begin{array}{c}\text { often } \\ \text { true }\end{array} & \begin{array}{c}\text { very often } \\ \text { or always true }\end{array} \\ 1 & 2 & 3 & 4 & 5\end{array}$

\begin{tabular}{|c|c|c|}
\hline 1 & I'm good at finding the words to describe my feelings & DS \\
\hline 2 & I can easily put my beliefs, opinions, and expectations into words & DS \\
\hline 3 & I watch my feelings without getting carried away by them & NR \\
\hline 4 & I tell myself that I shouldn't be feeling the way I'm feeling & $/ \mathrm{NJ}$ \\
\hline 5 & it's hard for me to find the words to describe what I'm thinking & $/ \mathrm{DS}$ \\
\hline 6 & $\begin{array}{l}\text { I pay attention to physical experiences, such as the } \\
\text { wind in my hair or sun on my face }\end{array}$ & $\mathrm{OB}$ \\
\hline 7 & I make judgments about whether my thoughts are good or bad. & $/ \mathrm{NJ}$ \\
\hline 8 & I find it difficult to stay focused on what's happening in the present moment & /AA \\
\hline 9 & $\begin{array}{l}\text { when I have distressing thoughts or images, I don't } \\
\text { let myself be carried away by them }\end{array}$ & NR \\
\hline 10 & $\begin{array}{l}\text { generally, I pay attention to sounds, such as clocks ticking, birds } \\
\text { chirping, or cars passing }\end{array}$ & $\mathrm{OB}$ \\
\hline 11 & $\begin{array}{l}\text { when I feel something in my body, it's hard for me } \\
\text { to find the right words to describe it }\end{array}$ & $/ \mathrm{DS}$ \\
\hline 12 & $\begin{array}{l}\text { it seems I am "running on automatic" without } \\
\text { much awareness of what I'm doing }\end{array}$ & /AA \\
\hline 13 & when I have distressing thoughts or images, I feel calm soon after & NR \\
\hline
\end{tabular}




\begin{tabular}{|l|l|l|l|}
\hline 14 & I tell myself I shouldn't be thinking the way I'm thinking & /NJ & \\
\hline 15 & I notice the smells and aromas of things & OB & \\
\hline 16 & even when I'm feeling terribly upset, I can find a way to put it into words & DS & \\
\hline 17 & I rush through activities without being really attentive to them & /AA & \\
\hline 18 & $\begin{array}{l}\text { usually when I have distressing thoughts or images I can } \\
\text { just notice them without reacting }\end{array}$ & NR & \\
\hline
\end{tabular}

PTO.

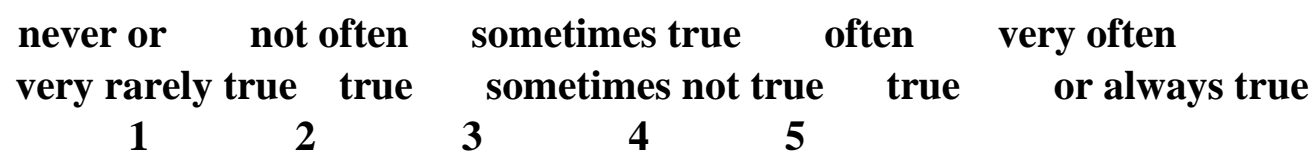

\begin{tabular}{|c|c|c|}
\hline 19 & $\begin{array}{l}\text { I think some of my emotions are bad or } \\
\text { inappropriate and I shouldn't feel them }\end{array}$ & $/ \mathrm{NJ}$ \\
\hline 20 & $\begin{array}{l}\text { I notice visual elements in art or nature, such as colors, shapes, } \\
\text { textures, or patterns of light and shadow }\end{array}$ & OB \\
\hline 21 & $\begin{array}{l}\text { when I have distressing thoughts or images, I just } \\
\text { notice them and let them go }\end{array}$ & NR \\
\hline 22 & I do jobs or tasks automatically without being aware of what I'm doing & /AA \\
\hline 23 & I find myself doing things without paying attention & /AA \\
\hline 24 & I disapprove of myself when I have illogical ideas & $/ \mathrm{NJ}$ \\
\hline
\end{tabular}




\section{Appendix C: Self-Compassion Scale-SF}

Please read each statement carefully before answering. To the left of each item, indicate how often you behave in the stated manner, using the following scale:

Almost

never

1

3

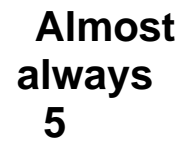

1. When I fail at something important to me I become consumed by feelings of inadequacy.

2. I try to be understanding and patient towards those aspects of my personality I don't like.

3. When something painful happens I try to take a balanced view of the situation.

4. When I'm feeling down, I tend to feel like most other people are probably happier than I am.

5. I try to see my failings as part of the human condition. need.

6. When I'm going through a very hard time, I give myself the caring and tenderness I

7. When something upsets me I try to keep my emotions in balance.

8. When I fail at something that's important to me, I tend to feel alone in my failure

9. When I'm feeling down I tend to obsess and fixate on everything that's wrong.

10. When I feel inadequate in some way, I try to remind myself that feelings of inadequacy are shared by most people.

11. I'm disapproving and judgmental about my own flaws and inadequacies.

12. I'm intolerant and impatient towards those aspects of my personality I don't like. 


\section{Appendix D: Advanced Warning of Relapse Scale}

Please read the following statements and for each one circle a number, from 1 to 7 , to indicate how much this has been true for you recently. Please circle one and only one number for every statement.

\begin{tabular}{|c|c|c|c|c|c|c|c|}
\hline & Never & Rarely & $\begin{array}{l}\text { Some- } \\
\text { times }\end{array}$ & $\begin{array}{l}\text { Fairly } \\
\text { often }\end{array}$ & Often & $\begin{array}{l}\text { Almost } \\
\text { always }\end{array}$ & Always \\
\hline $\begin{array}{l}\text { 1. I feel nervous or unsure of my ability to } \\
\text { stay clean of alcohol and/or drugs. }\end{array}$ & $\mathbf{1}$ & 2 & 3 & 4 & 5 & 6 & 7 \\
\hline 2. I have many problems in my life. & $\mathbf{1}$ & 2 & 3 & 4 & 5 & 6 & 7 \\
\hline 3. I tend to overreact or act impulsively. & 1 & 2 & 3 & 4 & 5 & 6 & 7 \\
\hline 4. I keep to myself and feel lonely. & $\mathbf{1}$ & 2 & 3 & 4 & 5 & 6 & 7 \\
\hline $\begin{array}{l}\text { 5. I get too focused on one area of my } \\
\text { life. }\end{array}$ & 1 & 2 & 3 & 4 & 5 & 6 & 7 \\
\hline 6. I feel blue, down, listless, or depressed. & 1 & 2 & 3 & 4 & 5 & 6 & 7 \\
\hline 7. I engage in wishful thinking. & 1 & 2 & 3 & 4 & 5 & 6 & 7 \\
\hline 8. The plans that I make succeed. & $\mathbf{1}$ & 2 & 3 & 4 & 5 & 6 & 7 \\
\hline $\begin{array}{l}\text { 9. I have trouble concentrating and prefer } \\
\text { to dream about how things could be. }\end{array}$ & $\mathbf{1}$ & 2 & 3 & 4 & 5 & 6 & 7 \\
\hline 10. Things don't work out well for me. & 1 & 2 & 3 & 4 & 5 & 6 & 7 \\
\hline 11. I feel confused. & $\mathbf{1}$ & 2 & 3 & 4 & 5 & 6 & 7 \\
\hline $\begin{array}{l}\text { 12. I get irritated or annoyed with my } \\
\text { friends. }\end{array}$ & $\mathbf{1}$ & 2 & 3 & 4 & 5 & 6 & 7 \\
\hline
\end{tabular}




\begin{tabular}{|l|l|l|l|l|l|l|l|}
\hline 13. I feel angry or frustrated. & $\mathbf{1}$ & $\mathbf{2}$ & $\mathbf{3}$ & $\mathbf{4}$ & $\mathbf{5}$ & $\mathbf{6}$ & $\mathbf{7}$ \\
\hline 14. I have good eating habits. & $\mathbf{1}$ & $\mathbf{2}$ & $\mathbf{3}$ & $\mathbf{4}$ & $\mathbf{5}$ & $\mathbf{6}$ & $\mathbf{7}$ \\
\hline
\end{tabular}

\begin{tabular}{|c|c|c|c|c|c|c|c|}
\hline $\begin{array}{l}\text { 15. I feel trapped and stuck, like there is } \\
\text { no way out. }\end{array}$ & 1 & 2 & 3 & 4 & 5 & 6 & 7 \\
\hline 16. I have trouble sleeping. & 1 & 2 & 3 & 4 & 5 & 6 & 7 \\
\hline $\begin{array}{l}\text { 17. I have long periods of serious } \\
\text { depression. }\end{array}$ & 1 & 2 & 3 & 4 & 5 & 6 & 7 \\
\hline 18. I don't really care what happens. & 1 & 2 & 3 & 4 & 5 & 6 & 7 \\
\hline $\begin{array}{l}\text { 19. I feel like things are so bad that I } \\
\text { might as well use substances. }\end{array}$ & 1 & 2 & 3 & 4 & 5 & 6 & 7 \\
\hline 20. I am able to think clearly. & 1 & 2 & 3 & 4 & 5 & 6 & 7 \\
\hline 21. I feel sorry for myself. & 1 & 2 & 3 & 4 & 5 & 6 & 7 \\
\hline 22. I think about using substances. & 1 & 2 & 3 & 4 & 5 & 6 & 7 \\
\hline 23. I lie to other people. & 1 & 2 & 3 & 4 & 5 & 6 & 7 \\
\hline 24. I feel hopeful and confident. & 1 & 2 & 3 & 4 & 5 & 6 & 7 \\
\hline 25. I feel angry at the world in general. & 1 & 2 & 3 & 4 & 5 & 6 & 7 \\
\hline $\begin{array}{l}\text { 26. I am doing things to stay clean of } \\
\text { alcohol and/or drugs. }\end{array}$ & 1 & 2 & 3 & 4 & 5 & 6 & 7 \\
\hline
\end{tabular}




\begin{tabular}{|l|l|l|l|l|l|l|l|}
\hline $\begin{array}{l}\text { 27. I am afraid that I am losing my mind. } \\
\text { 28. I am using alcohol and/or drugs out of } \\
\text { control. }\end{array}$ & 1 & 2 & 3 & 4 & 5 & 6 & 7 \\
\hline
\end{tabular}




\section{Appendix E: Substance Abuse Relapse and Demographics}

1. Which of the following describes your gender identity? (Circle One of the Following)

- Male

- Female

- TransM2F

- TransF2M

- Other:

2. What is your current age?

3. Which of the following best represents your ethnic/racial identity? (Circle One of the Following)

- African American or Black

- Asian American or Pacific Islander

- American Indian or Native American or Alaskan Native

- Arabic American or Middle Eastern

- Hispanic or Latino/a

- East Indian or Indian American

- Caucasian American or White

- Biracial or Multiracial American

- Other:

4. What is your primary drug of choice? (Please circle ONE of the following)

- Alcohol

- Crack

- Heroin

- Methamphetamine

- Cocaine

- Amphetamines "Uppers"

- Benzodiazepines "Benzos"

- Marijuana

- LSD

- PCP

- Other:

5. By your estimate, how many times would you say you have been in substance abuse treatment? 
6. By your estimate, how many times would you say you have relapsed in the past 6 months? (Must have had 1 week of continued sobriety before using)

7. How long have been in your current treatment?

8. By your estimate, what is your household income?

9. How often do you participate in group? 


\section{Appendix F: Recruitment Letter}

\section{W- WestVirginiaUniversity.}

Dear Participant,

This letter is a request for you to take part in a research project to assess how internal factors affect relapse risk among individuals recovering from substance use. This project is being conducted by Jonathan Nauser, doctoral candidate in the Department of Counseling, Rehabilitation Counseling, and Counseling Psychology at WVU under the supervision of Dr. Monica Leppma, Associate Professor in the College of Education and Human Services. Your participation in this project is greatly appreciated and will take approximately 20-30 minutes to fill out the attached questionnaire.

Your involvement in this project will be kept as confidential as legally possible. All data will be reported in the aggregate. You must be 18 years of age or older to participate. I will not ask any information that should lead back to your identity as a participant. Your participation is completely voluntary. You may skip any question that you do not wish to answer and you may discontinue at any time. Your treatment will not be affected if you decide either not to participate or to withdraw. West Virginia University's Institutional Review Board acknowledgement of this project is on file. Upon completion of the survey packet, you will be rewarded a $\$ 5.00$ Sheetz gift card for your participation.

I hope that you will participate in this research project, as it could be beneficial in understanding the impact of internal factors on relapse risk in individuals recovering from substance use. Thank you very much for your time. Should you have any questions about this letter or the research project, please feel free to contact Monica Leppma at (304) 293-0540 or by e-mail at monica.leppma@mail.wvu.edu.

Thank you for your time and help with this project.

Sincerely, 


\section{Appendix E: Informed Consent Form}

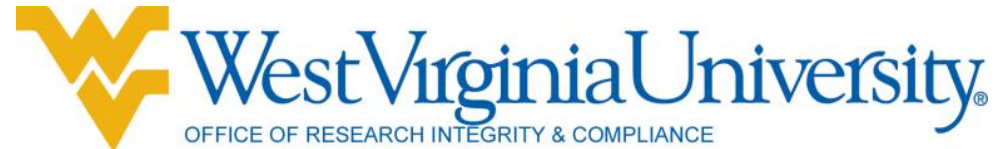

Human Research Protocol

Only Minimal Risk Consent Form

(With HIPAA)

\section{Only Minimal Risk \\ Consent Information and HIPAA Form}

Principal Investigator

Department

Protocol Number

Study Title

Assessing Variance Explained for Relapse Risk

Co-Investigator(s)

Sponsor (if any)

\section{Contact Persons}

If you have any questions, concerns, or complaints about this research, you can contact Jonathan Nauser via email atjwn0003@mix.wvu.edu.

In the event you experience any side effects or injury related to this research, you should contact Dr. Leppma at (304) 293-0540.

For information regarding your rights as a research subject, to discuss problems, concerns, or suggestions related to the research, to obtain information or offer input about the research, contact the Office of Research Integrity and Compliance at (304) 293-7073.

In addition, if you would like to discuss problems, concerns, have suggestions related to research, or would like to offer input about the research, contact the Office of Research Integrity and Compliance at 304-293-7073.

\section{Introduction}

You have been asked to participate in this research study, which has been explained to you by Jonathan Nauser. This study is being conducted by Jonathan Nauser \& Monica Leppma in the Department of Counseling, Rehabilitation Counseling, and Counseling Psychology at West Virginia University.

Purpose(s) of the Study 
The purpose of this study is to explore the personal factors that contribute to relapse risk among individuals recovering from substance abuse.

\section{Description of Procedures}

This study involves filling out a packet of questionnaires and will take approximately 20-30 minutes for you to complete. You will be asked to fill out questionnaires regarding your self-efficacy, trait mindfulness, selfcompassion, relapse risk, drug use history, and demographics. This will take approximately 20-30 minutes. You do not have to answer all the questions. You will have the opportunity to see the questionnaire before signing this consent form.

\section{Discomforts}

There are no known or expected risks from participating in this study, except for the mild frustration associated with answering the questions.

\section{Alternatives}

You do not have to participate in this study.

\section{Benefits}

You may not receive any direct benefit from this study. The knowledge gained from this study may eventually benefit others.

\section{Financial Considerations}

Each participant that agrees to participate in the study will be rewarded 1 of $100 \$ 5.00$ Sheetz gift cards. If you withdraw before the end of the study, you will not be rewarded one of the gift cards. If you successfully complete the study, you will then be rewarded 1 of $100 \$ 5.00$ Sheetz gift cards.

\section{Confidentiality}

Any information about you that is obtained as a result of your participation in this research will be kept as confidential as legally possible. Your research records and test results, just like hospital records, may be subpoenaed by court order or may be inspected by the study sponsor or federal regulatory authorities without your additional consent.

Audiotapes or videotapes will be kept locked up and will be destroyed as soon as possible after the research is finished.

In any publications that result from this research, neither your name nor any information from which you might be identified will be published without your consent.

\section{HIPAA}


We know that information about you and your health is private. We are dedicated to protecting the privacy of that information. Because of this promise, we must get your written authorization (permission) before we may use or disclose your protected health information or share it with others for research purposes.

You can decide to sign or not to sign this authorization section. However, if you choose not to sign this authorization, you will not be able to take part in the research study. Whatever choice you make about this research study will not have an effect on your access to medical care.

\section{Persons/Organizations Providing the Information}

Patient

\section{Persons/Organizations Receiving the Information}

- The research site(s) carrying out this study. This includes WVU. It also includes each site's research staff and medical staff.

- The members and staff of any Institutional Review Board (IRB) that oversees this research study.

\section{The Following Information Will Be Used}

Information that is collected during the study such as: history, demographic data, and study forms.

\section{The Information is Being Disclosed for the Following Reasons}

- $\quad$ Publication of study results (without identifying you)

\section{You May Cancel this Authorization at Any Time by Writing to the Principal Investigator}

Monica Leppma PhD monica.leppma@mail.wvu.edu

If you cancel this authorization, any information that was collected already for this study cannot be withdrawn.

Once information is disclosed, according to this authorization, the recipient may redisclose it and then the

information may no longer be protected by federal regulations.

You have a right to see and make copies of your medical records. You will not be able to see or copy your records related to the study until the sponsor has completed all work related to the study. At that time you may ask to see the study doctor's files related to your participation in the study and have the study doctor correct any information about you that is wrong.

This authorization will expire at the end of the study unless you cancel it before that time.

\section{Voluntary Participation}

Participation in this study is voluntary. You are free to withdraw your consent to participate in this study at any time.

Refusal to participate or withdrawal will not affect your treatment and will involve no penalty to you. Refusal to participate or withdrawal will not affect your future care at West Virginia University. 
In the event new information becomes available that may affect your willingness to participate in this study, this information will be given to you so that you can make an informed decision about whether or not to continue your participation.

You have been given the opportunity to ask questions about the research, and you have received answers concerning areas you did not understand.

Upon signing this form, you will receive a copy.

I willingly consent to participate in this research.

\section{Signatures}

Signature of Subject

Printed Name Date Time

The participant has had the opportunity to have questions addressed. The participant willingly agrees to be in the study.

Signature of Investigator or Co-Investigator

Printed Name Date Time

